\title{
Health-Related Quality of Life and Experiences of Sarcoma Patients during the COVID-19 Pandemic
}

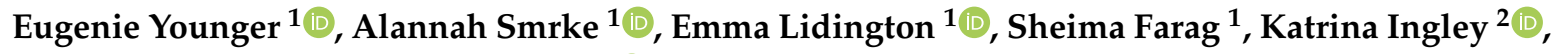 \\ Neha Chopra ${ }^{2}$, Alessandra Maleddu ${ }^{2}{ }^{-}$, Yolanda Augustin ${ }^{1}$, Eve Merry ${ }^{1}$, Roger Wilson ${ }^{3}$, \\ Charlotte Benson ${ }^{1}$, Aisha Miah ${ }^{1,4}$, Shane Zaidi ${ }^{1}$, Anne McTiernan ${ }^{2}$, Sandra J. Strauss ${ }^{2}$, \\ Palma Dileo ${ }^{2}$, Spyridon Gennatas ${ }^{1}\left(\mathbb{D}\right.$, Olga Husson $\left.{ }^{4,+}+\mathbb{(}\right)$ and Robin L. Jones ${ }^{1,4, *,+(\mathbb{C})}$ \\ 1 The Royal Marsden NHS Foundation Trust, London SW3 6JJ, UK; eugenie.younger@rmh.nhs.uk (E.Y.); \\ alannah.smrke@rmh.nhs.uk (A.S.); emma.lidington@rmh.nhs.uk (E.L.); sheima.farag@rmh.nhs.uk (S.F.); \\ yolanda.augustin@rmh.nhs.uk (Y.A.); eve.merry@nhs.net (E.M.); charlotte.benson@rmh.nhs.uk (C.B.); \\ aisha.miah@rmh.nhs.uk (A.M.); shane.zaidi@rmh.nhs.uk (S.Z.); spyridon.gennatas@rmh.nhs.uk (S.G.) \\ 2 University College London Hospitals NHS Foundation Trust, London NW1 2BU, UK; \\ katrina.ingley@nhs.net (K.I.); neha.chopra@nhs.net (N.C.); alessandra.maleddu@nhs.net (A.M.); \\ anne.mctiernan@nhs.net (A.M.); sandra.strauss@nhs.net (S.J.S.); palma.dileo@nhs.net (P.D.) \\ 3 Sarcoma Patients EuroNet e.V./Association, D-61200 Wolfersheim, Germany; \\ roger.wilson@sarcoma-patients.eu \\ 4 Institute of Cancer Research, London SM2 5NG, UK; olga.husson@icr.ac.uk \\ * Correspondence: robin.jones4@nhs.net; Tel.: +44-207-352-8171 \\ + These authors contributed equally.
}

Received: 14 June 2020; Accepted: 10 August 2020; Published: 14 August 2020

\begin{abstract}
Sarcomas are rare cancers with a spectrum of clinical needs and outcomes. We investigated care experiences and health-related quality of life (HRQoL) in sarcoma patients during the COVID-19 pandemic. Patients with appointments during the first two months of the UK lockdown were invited to complete a survey. Questions included views on care modifications, COVID-19 worry and psychosocial impact, and EORTC-QLQ-C30 items. 350 patients completed the survey; median age 58 (16-92) years. Care modifications included telemedicine (74\%) and postponement of appointments $(34 \%)$, scans $(34 \%)$ or treatment $(10 \%)$. Most felt the quality of care was not affected $(72 \%)$, however, social life (87\%) and emotional wellbeing (41\%) were affected. Worry about COVID-19 infection was moderately high (mean 5.8/10) and significantly related to higher cancer-related worry; associated with lower emotional functioning irrespective of treatment intent. Curative patients (44\%) with low resilient coping scores had significantly higher COVID-19 worry. Patients who did not know their treatment intent (22\%) had significantly higher COVID-19 worry and insomnia. In summary, care experiences were generally positive; however, cancer-related worry, low resilient coping and uncertainty about treatment intent were associated with COVID-19 worry. These patients may benefit from additional psychological support during the pandemic and beyond.
\end{abstract}

Keywords: sarcomas; HRQoL; COVID-19; patient experience

\section{Introduction}

The current COVID-19 pandemic caused by a novel betacoronavirus (SARS-CoV-2) is a global health emergency [1,2]. As of 1 June 2020, there have been nearly 6 million confirmed cases and over 350,000 deaths across the world [2]. Mitigation and containment measures, including social distancing and quarantine, have been widely implemented in attempts to delay transmission and reduce the number of fatalities [3,4]. On 23 March 2020, the government of the United Kingdom (UK) announced 
a national policy mandating the entire country to stay at home except for very limited purposes such as medical need or employment in key professions [5].

Although the majority of people with COVID-19 infection will have mild-moderate symptoms $(80 \%)$, the exponential rise in cases precipitated an unprecedented impact on international healthcare systems [6]. Up to $40 \%$ of hospitalised patients will require respiratory support and around $6 \%$ require mechanical ventilation [7-9]. Mortality rates are estimated to be between 1-4\% [10]. Risk factors for death include older age, Asian and Black ethnic origin, and pre-existing medical conditions such as diabetes, hypertension, coronary artery disease and obesity [1,11]. Patients with cancer may also be more susceptible to COVID-19 and complications due to pulmonary disease, immune compromise caused by malignancy or anti-cancer treatments, and exposure to the virus through frequent visits to healthcare facilities [12]. Early data from China demonstrated that patients with cancer had a higher mortality rate, compared to patients without cancer [13]. These findings have been supported by more recent data from Europe and the United States [14-16]. It was therefore deemed critical to implement effective, primary preventive measures to reduce exposure and minimise risk for patients with cancer.

On 20 March 2020, the National Institute for Clinical Excellence (NICE) published guidelines for the delivery of cancer care in the UK during the COVID-19 pandemic [17]. Recommendations included postponing non-essential procedures, selective conversion of appointments to telemedicine, and prioritising patients for systemic treatment [17]. Although the impact of modifications on patients with cancer has not been described, it is widely acknowledged that the pandemic has had a negative impact on mental health and wellbeing in the general population [18-21].

Sarcomas are rare, heterogeneous cancers of mesenchymal origin that can arise in patients of any age. Prognosis is widely variable and is related to factors such as histological subtype and disease stage. Due to the wide spectrum of clinical need and outcomes for these patients, this is a unique and relevant group of patients to study during the COVID-19 pandemic, representing a microcosm of all solid cancers. The primary aims of this study were to assess the impact of the COVID-19 pandemic on care experiences, worry and health-related quality of life (HRQoL) in patients with sarcomas.

\section{Results}

\subsection{Patient Characteristics}

Three hundred and fifty patients participated in the survey (response rate: $44 \%$; Appendix A). The median age of patients was 58 (range 16-92) years, with a slightly higher proportion of females $(n=192,55 \%)$ (Table 1). The majority were of Caucasian/European ethnic origin $(n=286,82 \%)$ and were well-educated (college/diploma/vocational qualification or higher) $(n=255,73 \%)$. Most patients were living with others $(n=303,87 \%)$ and had a partner $(n=245,70 \%)$. Co-morbidities associated with poor COVID-19 outcomes were infrequent; most common was hypertension $(n=76,22 \%)$. The majority of patients usually travelled more than one hour to reach their sarcoma centre ( $n=243,70 \%)$.

Table 1. Participant characteristics.

\begin{tabular}{|c|c|c|c|c|c|}
\hline Patient Characteristics & $\begin{array}{l}\text { All Participants } \\
(n=350) \\
n(\%)\end{array}$ & $\begin{array}{l}\text { Curative Intent } \\
\quad(n=150) \\
n(\%)\end{array}$ & $\begin{array}{l}\text { Palliative Intent } \\
(n=117) \\
n(\%)\end{array}$ & $\begin{array}{c}\text { Intent Unknown } \\
(n=77) \\
n(\%)\end{array}$ & $p$-Value \\
\hline \multicolumn{6}{|l|}{ Age (years) } \\
\hline $\begin{array}{c}\text { Mean } \\
\text { (SD) }\end{array}$ & $\begin{array}{c}56.1 \\
(17.3)\end{array}$ & $\begin{array}{c}52.0 \\
(17.9) \\
\end{array}$ & $\begin{array}{c}61.4 \\
(14.6) \\
\end{array}$ & $\begin{array}{c}56.3 \\
(17.8)\end{array}$ & 0.060 \\
\hline \multicolumn{6}{|l|}{ Gender } \\
\hline Male & $158(45)$ & $65(43)$ & $58(50)$ & $31(30)$ & \multirow{2}{*}{0.394} \\
\hline Female & $192(55)$ & $85(57)$ & $59(50)$ & $46(60)$ & \\
\hline \multicolumn{6}{|l|}{ Ethnicity } \\
\hline Caucasian/European & $286(82)$ & $121(81)$ & $100(87)$ & $59(77)$ & \multirow{2}{*}{0.168} \\
\hline Other & $62(18)$ & $29(19)$ & $15(13)$ & $18(23)$ & \\
\hline
\end{tabular}


Table 1. Cont.

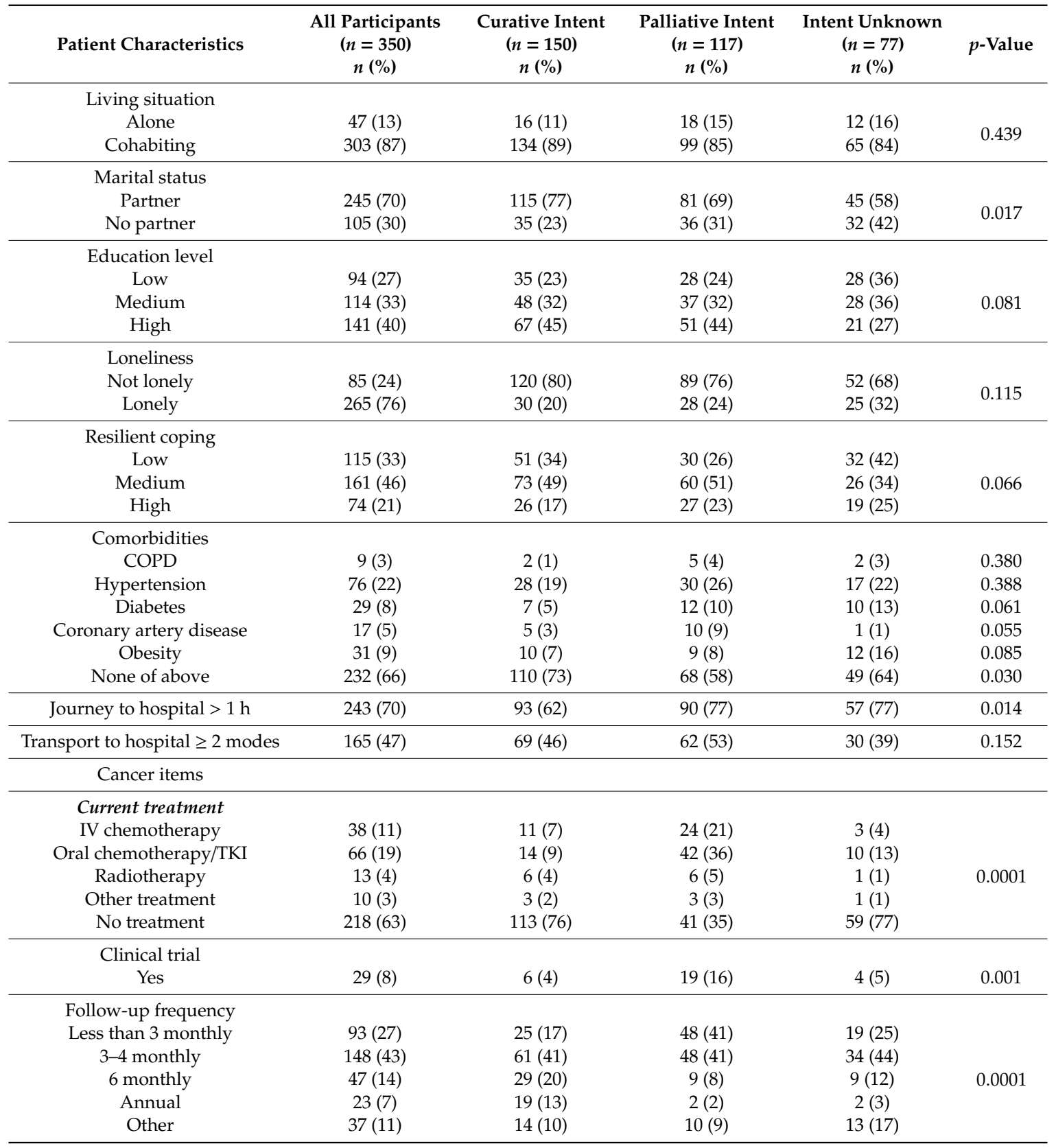

\subsection{Loneliness}

Around half the patients felt isolated; 130 patients (37\%) felt isolated some of the time and 78 $(11 \%)$ often felt isolated. Overall, 85 patients $(24 \%)$ were lonely and 265 patients were not lonely $(76 \%)$. Loneliness was associated with younger age; adolescents and young adults (aged 16-39 years; $33 \%$ ), middle-aged (aged 40-64; 29\%), elderly (aged $\geq 65$ years; 15\%); $p=0.004$. Loneliness was also more common in patients who were not of Caucasian/European ethnic origin (36\% vs. $22 \%$ Caucasian/European; $p=0.021)$, patients who were living alone ( $51 \%$ vs. $20 \%$ cohabiting; $p=0.0001)$, and those without a partner $(41 \%$ vs. $17 \%$ with partner; $p=0.0001)$.

\subsection{Resilient Coping}

Participants had a mean resilient coping score of $14.6(\mathrm{SD}=2.7)$ suggesting most participants were low to medium resilient copers. One hundred and fifteen patients (33\%) scored less than 14 points 
(low resilient copers), 161 patients (46\%) scored between 14 and 16 points (medium resilient copers) and 74 patients $(21 \%)$ were high resilient copers.

\subsection{Treatment Characteristics}

The majority of patients reported that the intent of their treatment or management plan was curative/no evidence of disease $(n=150,44 \%)$ or palliative $(n=117,34 \%)$, however, 77 patients $(22 \%)$ did not know their treatment intent (unknown intent). One hundred and twenty-seven patients $(36 \%)$ were currently receiving treatment for sarcoma; intravenous chemotherapy $(n=38,11 \%)$, oral anti-cancer treatments $(n=66,19 \%)$, radiotherapy $(n=13,4 \%)$ and other treatments such as microwave ablation $(n=10,3 \%)$. Twenty-nine patients $(8 \%)$ were taking part in a clinical trial.

\subsection{COVID-19: Worry and Psychosocial Impact}

Mean overall level of worry about the impact of COVID-19 on personal health was 5.8 out of 10 (standard deviation \{SD 2.5). Of all respondents, patients who did not know their treatment intent were the most worried about COVID-19 (6.5/10) compared to patients with palliative intent (6.0/10) or curative intent $(5.4 / 10)$ treatment $(p=0.004)$. Mean level of worry about sarcoma was 5.5/10 (SD 2.6) and was highest among patients treated with palliative intent. Figure 1 demonstrates the mean level of worry about COVID-19 and sarcoma according to treatment intent and current treatment status (on active treatment versus not on treatment). In patients treated with curative intent, patients on active treatment were significantly more worried about sarcoma $(p=0.016)$ and about COVID-19 $(p=0.040)$ compared to curative patients who were not on active treatment. Patients who did not know their treatment intent (unknown group) and were on active treatment were also significantly more worried about COVID-19 $(p=0.005)$ and were more worried about sarcoma than those not on treatment, although this did not reach statistical significance $(p=0.054)$. Treatment status in palliative patients was not associated with sarcoma worry or COVID-19 worry.

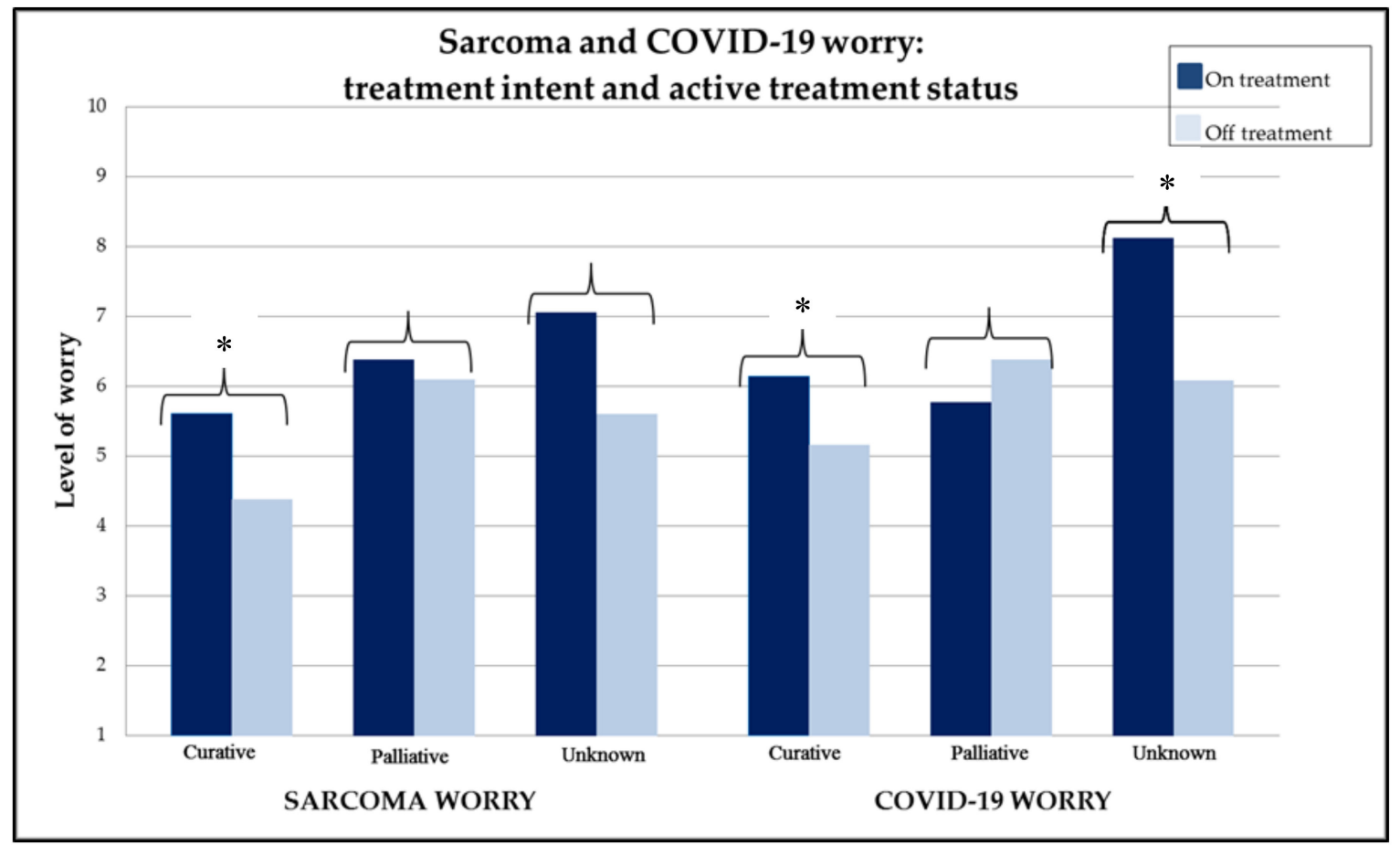

Figure 1. Sarcoma and COVID-19 worry according to treatment intent and active treatment status. * $p<0.05$. 
Around half the patients thought that they were at a higher risk of COVID-19 than the general population ( $n=167,48 \%$ ) (Table 2 ). Patients with co-morbidities associated with poor COVID-19 outcomes (56\% vs. $44 \%$ no comorbidities; $p=0.049)$, who were lonely $(62 \%$ vs. $38 \%$ not lonely; $p=0.002)$ or on treatment $(60 \%$ vs. $40 \% ; p=0.001)$ were more likely to report a higher perceived risk of COVID-19. No participants had confirmed COVID-19 infection. Of the 40 patients (11\%) reporting symptoms of COVID-19, six patients tested negative (2\%) while others were not tested. The COVID-19 pandemic impacted finances $(n=84,24 \%)$, employment $(n=86,25 \%)$, emotional wellbeing $(n=145$, $41 \%)$, family life $(n=210,60 \%)$ and social life/activities $(n=306,87 \%)$. The majority of patients $(n=255,73 \%)$ indicated that they would accept ventilation in the event of a potentially life-threatening respiratory disease, however, a considerable proportion were not sure $(n=75,22 \%)$.

Table 2. COVID-19 items.

\begin{tabular}{|c|c|c|c|c|c|}
\hline COVID-19 Items & $\begin{array}{c}\text { All } \\
n(\%)\end{array}$ & $\begin{array}{c}\text { Curative Intent } \\
n(\%)\end{array}$ & $\begin{array}{c}\text { Palliative Intent } \\
n(\%)\end{array}$ & $\begin{array}{c}\text { Intent Unknown } \\
n(\%)\end{array}$ & $p$-Value \\
\hline \multicolumn{6}{|l|}{ Perceived risk vs. } \\
\hline Higher & $167(48)$ & $52(35)$ & $70(60)$ & $44(57)$ & \multirow{4}{*}{0.0001} \\
\hline Equal & $135(39)$ & $77(51)$ & $30(26)$ & $26(34)$ & \\
\hline Lower & $30(9)$ & $14(9)$ & $13(11)$ & $1(1)$ & \\
\hline Do not know & $18(5)$ & $7(5)$ & $4(3)$ & $6(8)$ & \\
\hline \multicolumn{6}{|l|}{ COVID-19 symptoms/test } \\
\hline Symptoms, negative test & $6(2)$ & $5(3)$ & $1(1)$ & $0(0)$ & \multirow{4}{*}{0.150} \\
\hline Symptoms, no test & $34(10)$ & $15(10)$ & $13(11)$ & $6(8)$ & \\
\hline No symptoms & $265(76)$ & $113(75)$ & $91(78)$ & $55(71)$ & \\
\hline Do not know & $45(13)$ & $17(11)$ & $12(10)$ & $16(21)$ & \\
\hline \multicolumn{6}{|l|}{ COVID-19 pandemic impact } \\
\hline Employment & $86(25)$ & $37(25)$ & $32(27)$ & $15(20)$ & 0.459 \\
\hline Financial situation & $84(24)$ & $33(22)$ & $29(25)$ & $21(27)$ & 0.661 \\
\hline Family life & $210(60)$ & $85(57)$ & $79(68)$ & $42(55)$ & 0.112 \\
\hline Emotional wellbeing & $145(41)$ & $62(41)$ & $48(41)$ & $33(43)$ & 0.979 \\
\hline Social life/activities & $306(87)$ & $130(87)$ & $103(88)$ & $67(87)$ & 0.978 \\
\hline \multicolumn{6}{|l|}{ Would accept ventilator } \\
\hline Yes & $255(73)$ & $119(79)$ & $82(70)$ & $50(65)$ & \multirow{3}{*}{0.175} \\
\hline No & $19(5)$ & $6(4)$ & $8(7)$ & $5(7)$ & \\
\hline Do not know & $75(22)$ & $25(17)$ & $27(23)$ & $22(29)$ & \\
\hline
\end{tabular}

\subsection{Experiences of Care during COVID-19 Pandemic}

A large proportion of patients who reported having an appointment $(n=286,82 \%)$ had a telemedicine consultation (telephone/video) $(n=211,74 \%)$ (Table 3). Satisfaction with telemedicine was generally high; telephone appointment mean score 8.7/10 (SD 1.7), video appointment mean score 7.4/10 (SD 3.4). Satisfaction with face to face appointments was also high 8.4/10 (SD 2.6). Nearly three-quarters of patients $(n=259,74 \%)$ indicated preference for some telemedicine appointments in the future, however, 78 patients $(22 \%)$ would prefer face to face appointments only. Resilient coping level ( $p=0.024)$ and treatment intent $(p=0.047)$ were significantly associated with preference for face to face appointments only; patients with a low resilient coping score, and those who were uncertain about their treatment intent were most likely to prefer face to face appointments. Most participants who preferred face to face appointments indicated it was more reassuring $(n=58,74 \%)$. Preference for some telemedicine appointments was due to reduced travel time $(n=121, n=47 \%)$, cost of travel ( $n=60,23 \%)$, or convenience $(n=89,34 \%)$. Patient characteristics (e.g., age), treatment intent and journey time to hospital were not associated with appointment preferences.

Around one third of patients had their follow-up appointments $(n=117,34 \%)$ or scans $(n=106$, $31 \%$ ) postponed by at least three months (Table 3 ). Patient age was associated with postponement of appointments $(p=0.016)$; patients aged $\geq 65$ years were the most likely to have postponed appointments 
(43\%). Treatment was paused or discontinued for a minority of patients $(n=34,10 \%)$. Six patients reported that trial participation had been paused due to the pandemic. A further nine patients were being considered for trial enrolment, but participation was put on hold due to the pandemic.

Postponement of treatment was significantly associated with treatment intent $(p=0.0001)$; most common among patients treated with palliative intent (Table 3). Patients generally indicated that postponement of appointments and scans were good decisions (70\% and 59\%, respectively). Patients treated with palliative intent were significantly more likely to be unsure whether postponement of treatment was a good or bad decision (neutral) compared to those treated with curative or unknown intent $(p=0.032)$.

Participants were most likely to contact their sarcoma clinical nurse specialist ( $n=272,78 \%$ ) or the Royal Marsden National Health Service (NHS) Foundation Trust (RMH) or University College London Hospitals NHS Foundation Trust (UCLH) helpline $(n=179,51 \%)$ in cases of cancer-related concerns. Almost two-thirds of participants felt able to contact the healthcare team as normal ( $n=223,64 \%$ ), however, a substantial number indicated that they would only contact their team in an emergency situation $(n=95,27 \%)$.

Table 3. Patient reported experiences of care.

\begin{tabular}{|c|c|c|c|c|c|}
\hline Experiences of Care & $\begin{array}{c}\text { All } \\
\text { Participants }\end{array}$ & $\begin{array}{l}\text { Curative } \\
\text { Intent }\end{array}$ & $\begin{array}{l}\text { Palliative } \\
\text { Intent }\end{array}$ & $\begin{array}{c}\text { Intent } \\
\text { Unknown }\end{array}$ & $p$-Value \\
\hline \multicolumn{6}{|l|}{ Appointment type } \\
\hline Face to face appointment & $75(26)$ & $32(27)$ & $35(33)$ & $8(14)$ & \multirow{2}{*}{0.003} \\
\hline Telemedicine appointment & $211(74)$ & $86(73)$ & $70(67)$ & $51(86)$ & \\
\hline \multicolumn{6}{|l|}{ Preferred appointment type } \\
\hline Face to face (F2F) only * & $78(22)$ & $29(19)$ & $25(22)$ & $23(30)$ & \multirow{5}{*}{0.047} \\
\hline Mostly F2F, occasional telemedicine & $129(37)$ & $68(45)$ & $36(31)$ & $23(30)$ & \\
\hline Mostly telemedicine, occasional F2F & $118(34)$ & $44(29)$ & $48(41)$ & $23(30)$ & \\
\hline Only telemedicine & $12(4)$ & $6(4)$ & $4(3)$ & $2(3)$ & \\
\hline Unsure & $12(4)$ & $3(2)$ & $3(3)$ & $6(8)$ & \\
\hline \multicolumn{6}{|l|}{ Appointment modification } \\
\hline Postponed & $117(34)$ & $48(33)$ & $40(35)$ & $28(36)$ & 0.853 \\
\hline \multicolumn{6}{|l|}{ Opinion on postponement } \\
\hline Positive & $82(70)$ & $39(81)$ & $24(60)$ & $18(64)$ & \multirow{3}{*}{0.220} \\
\hline Negative & $10(9)$ & $2(4)$ & $4(10)$ & $4(14)$ & \\
\hline Neutral & $24(21)$ & $7(15)$ & $11(28)$ & $6(21)$ & \\
\hline \multicolumn{6}{|l|}{ Imaging modification } \\
\hline Postponed & $106(31)$ & $42(29)$ & $33(30)$ & $28(37)$ & 0.422 \\
\hline \multicolumn{6}{|l|}{ Opinion on postponement } \\
\hline Positive & $63(59)$ & $28(67)$ & $18(55)$ & $14(50)$ & \multirow{3}{*}{0.212} \\
\hline Negative & $11(10)$ & $2(5)$ & $3(9)$ & $6(21)$ & \\
\hline Neutral & $32(30)$ & $12(29)$ & $12(36)$ & $8(29)$ & \\
\hline \multicolumn{6}{|l|}{ Treatment modification } \\
\hline Postponed & $29(9)$ & $5(3)$ & $20(18)$ & $4(5)$ & \multirow{2}{*}{0.0001} \\
\hline Discontinued & $5(2)$ & $2(1)$ & $3(3)$ & $0(0)$ & \\
\hline \multicolumn{6}{|l|}{ Opinion on postponed/stopped } \\
\hline Positive & $14(48)$ & $3(75)$ & $8(40)$ & $3(75)$ & \multirow{3}{*}{0.093} \\
\hline Negative & $2(7)$ & $1(25)$ & $1(5)$ & $0(0)$ & \\
\hline Neutral & $12(41)$ & $0(0)$ & $11(55)$ & $1(25)$ & \\
\hline \multicolumn{6}{|l|}{ Impact of pandemic on care quality } \\
\hline Positive & $4(1)$ & $3(2)$ & $0(0)$ & $1(1)$ & \multirow{4}{*}{0.155} \\
\hline Negative & $50(15)$ & $18(12)$ & $23(20)$ & $8(10)$ & \\
\hline Not affected & $250(72)$ & $113(76)$ & $78(68)$ & $55(71)$ & \\
\hline Unsure & $42(12)$ & $14(10)$ & $14(12)$ & $13(17)$ & \\
\hline
\end{tabular}


Table 3. Cont.

\begin{tabular}{|c|c|c|c|c|c|}
\hline Experiences of Care & $\begin{array}{c}\text { All } \\
\text { Participants }\end{array}$ & $\begin{array}{l}\text { Curative } \\
\text { Intent }\end{array}$ & $\begin{array}{l}\text { Palliative } \\
\text { Intent }\end{array}$ & $\begin{array}{c}\text { Intent } \\
\text { Unknown }\end{array}$ & $p$-Value \\
\hline \multicolumn{6}{|l|}{ Informed about care plan } \\
\hline Very well informed & $190(55)$ & $94(63)$ & $57(49)$ & $35(47)$ & \multirow{4}{*}{0.017} \\
\hline Informed & $126(36)$ & $44(30)$ & $53(45)$ & $27(36)$ & \\
\hline Little information & $23(7)$ & $8(5)$ & $5(4)$ & $10(13)$ & \\
\hline Not informed & $8(2)$ & $3(2)$ & $2(2)$ & $3(4)$ & \\
\hline \multicolumn{6}{|l|}{ Contacting HCP during pandemic ** } \\
\hline Contact as normal & $223(64)$ & $98(66)$ & $79(68)$ & $44(57)$ & \multirow{4}{*}{0.019} \\
\hline Worried about availability & $19(5)$ & $6(4)$ & $10(9)$ & $2(3)$ & \\
\hline Only if essential & $95(27)$ & $39(26)$ & $28(24)$ & $25(33)$ & \\
\hline Do not know & $12(3)$ & $6(4)$ & $0(0)$ & $6(8)$ & \\
\hline \multicolumn{6}{|l|}{ Contact for cancer support } \\
\hline Clinical nurse specialist & $272(78)$ & $114(76)$ & $96(82)$ & $60(78)$ & 0.482 \\
\hline Sarcoma helpline (RMH/UCLH) & $179(51)$ & $80(53)$ & $61(52)$ & $33(43)$ & 0.300 \\
\hline General practitioner (GP) & $72(21)$ & $29(19)$ & $22(19)$ & $29(26)$ & 0.420 \\
\hline NHS helpline & $15(4)$ & $5(3)$ & $4(3)$ & $5(7)$ & 0.474 \\
\hline Sarcoma charity & $19(5)$ & $10(7)$ & $5(4)$ & $4(5)$ & 0.690 \\
\hline Cancer charity (any) & $44(13)$ & $14(9)$ & $22(19)$ & $8(10)$ & 0.055 \\
\hline Online peer support & $16(5)$ & $6(4)$ & $6(5)$ & $4(5)$ & 0.880 \\
\hline
\end{tabular}

Abbreviations: ${ }^{*}$ F2F: face to face. ${ }^{* *} \mathrm{HCP}$ : healthcare professional.

\subsection{Health-Related Quality of Life (HRQoL)}

Figure 2 compares the HRQoL of participants according to the self-reported treatment intent and the UK normative population values (non-pandemic) [22]. Significant differences according to treatment intent were observed in the domains of physical functioning $(p=0.0001)$, role functioning ( $p=0.001)$, social functioning $(p=0.004)$, global health/QoL $(p=0.0001)$ and insomnia $(p=0.033)$. For these domains, patients treated with palliative intent had worse functioning, worse global HRQoL and higher insomnia scores than patients treated with curative intent. Patients who did not know the intent of their treatment had scores that fell between the curative group and palliative group for all of these domains except insomnia; these patients had the highest levels of insomnia. Cognitive and emotional functioning scores were also lower in this group, however, differences in these domains were not statistically significant. Patients treated with curative intent appeared to have higher physical, emotional and cognitive functioning, higher global HRQoL scores and lower insomnia scores, than the UK normative population during "non-pandemic" times.

\subsection{Multivariate Analysis: Cancer Worry and COVID-19 Worry}

After controlling for potential covariates, higher worry about the potential impact of COVID-19 on personal health was associated with significantly higher worry about sarcoma, irrespective of treatment intent $(p=0.0001)$ (Table 4$)$. In patients treated with curative intent, higher COVID-19 worry was associated with lower resilient coping $(p=0.012)$. For patients who were unsure of their treatment intent (unknown intent), higher COVID-19 worry was associated with lower global HRQoL ( $p=0.012$ ).

Higher level of worry about sarcoma was associated with significantly lower emotional functioning across all groups. In patients treated with palliative intent, higher level of worry about sarcoma was associated with the pandemic having an impact on social life/activities $(p=0.039)$. Patients having palliative treatment and who were more worried about sarcoma were less likely to have a telemedicine appointment $(p=0.001)$. For patients who did not know their treatment intent, higher level of worry about sarcoma was associated with being on treatment $(p=0.038)$. 


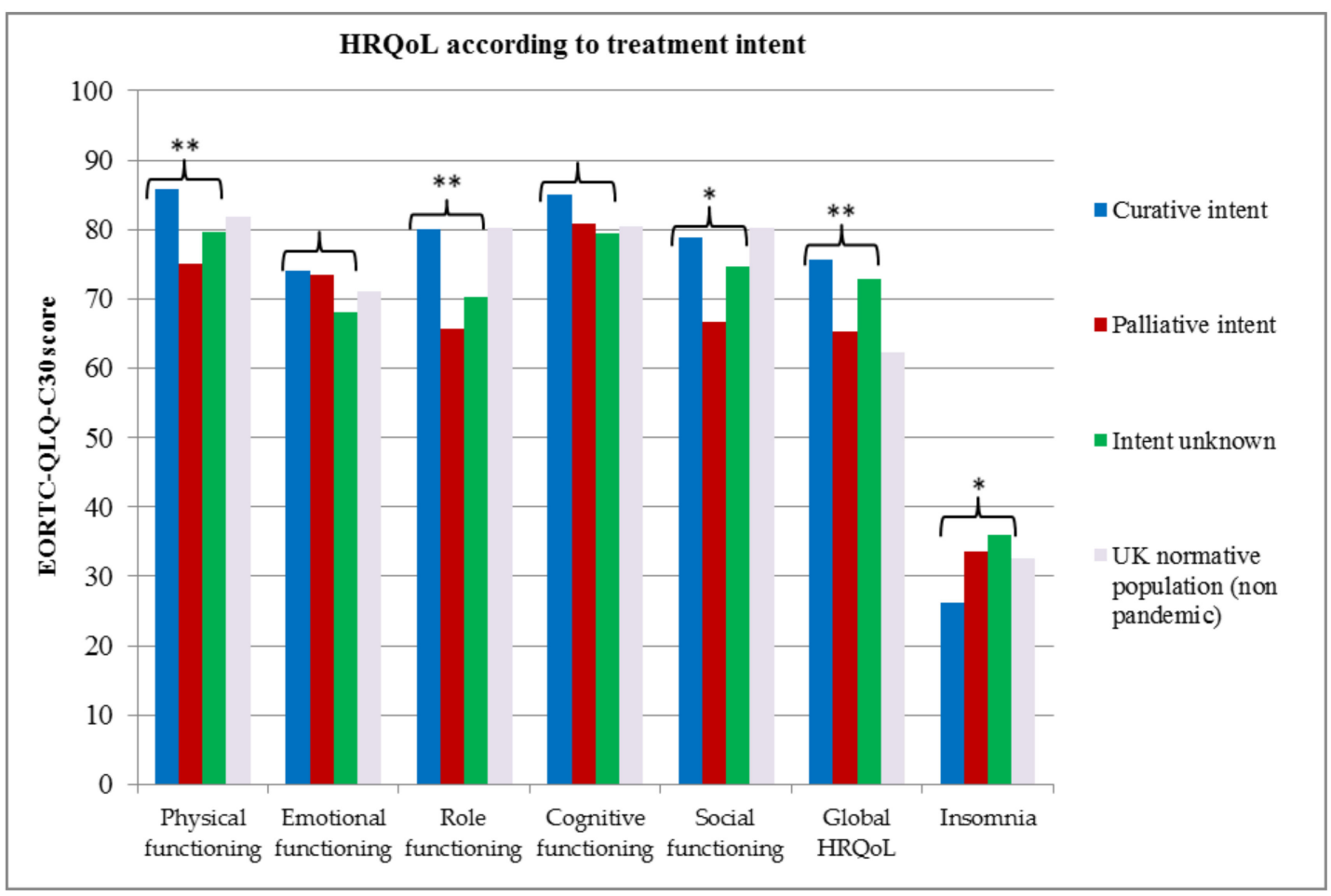

Figure 2. Health-related quality of life according to treatment intent. $p$-values: ${ }^{*} p \leq 0.05,{ }^{* *} p \leq 0.001$.

Table 4. Multivariate linear regression: factors associated with sarcoma worry and COVID-19 worry.

\begin{tabular}{|c|c|c|c|c|c|c|}
\hline \multirow[b]{2}{*}{ Patient Factors } & \multicolumn{3}{|c|}{ Worry about COVID-19 on Health } & \multicolumn{3}{|c|}{ Worry about Sarcoma } \\
\hline & $\begin{array}{l}\text { Curative } \\
\text { Intent }\end{array}$ & $\begin{array}{l}\text { Palliative } \\
\text { Intent }\end{array}$ & $\begin{array}{l}\text { Unknown } \\
\text { Intent }\end{array}$ & $\begin{array}{l}\text { Curative } \\
\text { Intent }\end{array}$ & $\begin{array}{l}\text { Palliative } \\
\text { Intent }\end{array}$ & $\begin{array}{c}\text { Unknown } \\
\text { Intent }\end{array}$ \\
\hline Age (continuous) & - & - & - & - & $\begin{array}{c}\beta=-0.026 \\
p=0.782\end{array}$ & - \\
\hline $\begin{array}{c}\text { Ethnicity } \\
\text { (Caucasian vs. other) }\end{array}$ & - & - & $\begin{array}{l}\beta=0.102 \\
p=0.233\end{array}$ & - & - & - \\
\hline Loneliness (continuous) & $\begin{array}{l}\beta=0.077 \\
p=0.393\end{array}$ & - & - & $\begin{array}{c}\beta=-0.110 \\
p=0.242\end{array}$ & - & - \\
\hline $\begin{array}{l}\text { Resilient coping } \\
\text { (continuous) }\end{array}$ & $\begin{array}{c}\beta=-0.206 \\
p=0.012\end{array}$ & - & - & $\begin{array}{c}\beta=-0.060 \\
p=0.475\end{array}$ & - & - \\
\hline Comorbidities (Yes/No) & - & - & - & - & $\begin{array}{c}\beta=-0.127 \\
p=0.160\end{array}$ & - \\
\hline \multicolumn{7}{|l|}{ Care Factors } \\
\hline On treatment $(\mathrm{Yes} / \mathrm{No})$ & $\begin{array}{l}\beta=0.056 \\
p=0.475\end{array}$ & - & $\begin{array}{l}\beta=0.175 \\
p=0.062\end{array}$ & $\begin{array}{l}\beta=0.116 \\
p=0.183\end{array}$ & - & $\begin{array}{l}\beta=0.221 \\
p=0.038\end{array}$ \\
\hline Telemedicine (Yes/No) & - & - & - & $\begin{array}{c}\beta=-0.101 \\
p=0.232\end{array}$ & $\begin{array}{c}\beta=-0.282 \\
p=0.001\end{array}$ & $\begin{array}{c}\beta=-0.069 \\
p=0.525\end{array}$ \\
\hline $\begin{array}{c}\text { Appointment } \\
\text { postponed (Yes/No) }\end{array}$ & - & - & - & $\begin{array}{c}\beta=-0.057 \\
p=0.494\end{array}$ & - & - \\
\hline $\begin{array}{c}\text { Treatment postponed } \\
\text { (Yes/No) }\end{array}$ & - & - & - & - & $\begin{array}{l}\beta=0.094 \\
p=0.260\end{array}$ & - \\
\hline
\end{tabular}


Table 4. Cont.

\begin{tabular}{|c|c|c|c|c|c|c|}
\hline \multirow[b]{2}{*}{ Patient Factors } & \multicolumn{3}{|c|}{ Worry about COVID-19 on Health } & \multicolumn{3}{|c|}{ Worry about Sarcoma } \\
\hline & $\begin{array}{l}\text { Curative } \\
\text { Intent }\end{array}$ & $\begin{array}{l}\text { Palliative } \\
\text { Intent }\end{array}$ & $\begin{array}{l}\text { Unknown } \\
\text { Intent }\end{array}$ & $\begin{array}{l}\text { Curative } \\
\text { Intent }\end{array}$ & $\begin{array}{l}\text { Palliative } \\
\text { Intent }\end{array}$ & $\begin{array}{l}\text { Unknown } \\
\text { Intent }\end{array}$ \\
\hline \multicolumn{7}{|l|}{ Impact of Pandemic } \\
\hline $\begin{array}{l}\text { Financial impact } \\
(\text { Yes/No) }\end{array}$ & - & - & $\begin{array}{l}\beta=0.037 \\
p=0.690\end{array}$ & - & $\begin{array}{l}\beta=0.064 \\
p=0.438\end{array}$ & - \\
\hline Family impact (Yes/No) & - & $\begin{array}{l}\beta=0.090 \\
p=0.300\end{array}$ & $\begin{array}{l}\beta=0.036 \\
p=0.696\end{array}$ & - & & $\begin{array}{l}\beta=0.041 \\
p=0.716\end{array}$ \\
\hline $\begin{array}{l}\text { Emotional impact } \\
(\text { Yes/No) }\end{array}$ & $\begin{array}{l}\beta=0.173 \\
p=0.056\end{array}$ & $\begin{array}{l}\beta=0.175 \\
p=0.071\end{array}$ & $\begin{array}{l}\beta=0.048 \\
p=0.620\end{array}$ & - & $\begin{array}{c}\beta=-0.060 \\
p=0.541\end{array}$ & $\begin{array}{l}\beta=0.180 \\
p=0.117\end{array}$ \\
\hline $\begin{array}{l}\text { Social life impact } \\
\text { (Yes/No) }\end{array}$ & - & $\begin{array}{l}\beta=0.119 \\
p=0.173\end{array}$ & & - & $\begin{array}{l}\beta=0.171 \\
p=0.039\end{array}$ & - \\
\hline \multicolumn{7}{|l|}{ HRQoL } \\
\hline $\begin{array}{l}\text { Sarcoma worry } \\
\text { (continuous) }\end{array}$ & $\begin{array}{c}\beta=0.340 \\
p=0.0001\end{array}$ & $\begin{array}{c}\beta=0.464 \\
p=0.0001\end{array}$ & $\begin{array}{c}\beta=0.582 \\
p=0.0001\end{array}$ & - & - & - \\
\hline $\begin{array}{l}\text { Physical functioning } \\
\text { (continuous) }\end{array}$ & $\begin{array}{c}\beta=-0.187 \\
p=0.122\end{array}$ & $\begin{array}{c}\beta=-0.011 \\
p=0.928\end{array}$ & $\begin{array}{c}\beta=-0.009 \\
p=0.941\end{array}$ & $\begin{array}{c}\beta=-0.051 \\
p=0.686\end{array}$ & $\begin{array}{c}\beta=-0.037 \\
p=0.758\end{array}$ & $\begin{array}{l}\beta=0.114 \\
p=0.424\end{array}$ \\
\hline $\begin{array}{l}\text { Emotional functioning } \\
\text { (continuous) }\end{array}$ & $\begin{array}{l}\beta=0.054 \\
p=0.661\end{array}$ & $\begin{array}{l}\beta=0.011 \\
p=0.923\end{array}$ & $\begin{array}{l}\beta=0.105 \\
p=0.427\end{array}$ & $\begin{array}{l}\beta=-0.409 \\
p=0.0001\end{array}$ & $\begin{array}{l}\beta=-0.410 \\
p=0.0001\end{array}$ & $\begin{array}{l}\beta=-0.572 \\
p=0.0001\end{array}$ \\
\hline $\begin{array}{l}\text { Role functioning } \\
\text { (continuous) }\end{array}$ & $\begin{array}{l}\beta=0.065 \\
p=0.547\end{array}$ & $\begin{array}{c}\beta=-0.058 \\
p=0.644\end{array}$ & $\begin{array}{l}\beta=0.013 \\
p=0.915\end{array}$ & $\begin{array}{c}\beta=-0.103 \\
p=0.370\end{array}$ & $\begin{array}{l}\beta=0.101 \\
p=0.423\end{array}$ & $\begin{array}{c}\beta=-0.101 \\
p=0.510\end{array}$ \\
\hline $\begin{array}{l}\text { Cognitive functioning } \\
\text { (continuous) }\end{array}$ & $\begin{array}{l}\beta=0.030 \\
p=0.778\end{array}$ & $\begin{array}{c}\beta=-0.109 \\
p=0.283\end{array}$ & $\begin{array}{l}\beta=0.136 \\
p=0.218\end{array}$ & $\begin{array}{l}\beta=0.215 \\
p=0.061\end{array}$ & - & $\begin{array}{l}\beta=0.046 \\
p=0.735\end{array}$ \\
\hline $\begin{array}{l}\text { Social functioning } \\
\text { (continuous) }\end{array}$ & $\begin{array}{c}\beta=-0.129 \\
p=0.218\end{array}$ & $\begin{array}{l}\beta=0.012 \\
p=0.925\end{array}$ & $\begin{array}{l}\beta=0.067 \\
p=0.571\end{array}$ & $\begin{array}{c}\beta=-0.098 \\
p=0.364\end{array}$ & $\begin{array}{c}\beta=-0.201 \\
p=0.127\end{array}$ & $\begin{array}{c}\beta=-0.187 \\
p=0.192\end{array}$ \\
\hline $\begin{array}{l}\text { Global HRQoL } \\
\text { (continuous) }\end{array}$ & $\begin{array}{l}\beta=0.064 \\
p=0.540\end{array}$ & $\begin{array}{l}\beta=0.108 \\
p=0.347\end{array}$ & $\begin{array}{c}\beta=-0.285 \\
p=0.012\end{array}$ & $\begin{array}{l}\beta=0.032 \\
p=0.775\end{array}$ & $\begin{array}{c}\beta=-0.051 \\
p=0.662\end{array}$ & $\begin{array}{l}\beta=0.117 \\
p=0.404\end{array}$ \\
\hline Insomnia (continuous) & $\begin{array}{c}\beta=-0.042 \\
p=0.639\end{array}$ & - & $\begin{array}{l}\beta=0.238 \\
p=0.053\end{array}$ & $\begin{array}{l}\beta=0.088 \\
p=0.353\end{array}$ & - & $\begin{array}{c}\beta=-0.166 \\
p=0.259\end{array}$ \\
\hline
\end{tabular}

\section{Discussion}

To our knowledge this is the first study to assess care experiences and HRQoL among adult patients with sarcomas during the COVID-19 pandemic. A substantial proportion of follow-up appointments and scans were postponed, and many patients were monitored remotely through telemedicine (telephone or video consultations). These modifications were generally perceived to be good decisions and most patients felt able to contact their healthcare professionals as normal. Treatment was not commonly postponed; patients undergoing palliative treatment were less certain whether this was a good or bad decision. Patients with high levels of worry about cancer were the most worried about the potential impact of COVID-19 on their health and had lower emotional functioning, irrespective of treatment intent. Low resilient coping scores were also related to higher COVID-19 worry in curative patients. Early identification of patients with low resilience and cancer-related worry may facilitate timely psychological support across the disease trajectory. Patients who reported unknown treatment intent experienced high levels of worry about COVID-19 and sarcoma, lower emotional functioning, and had high levels of insomnia. Treatment goals should be discussed at appropriate time points taking into account individual preferences for information provision, such as disclosure of prognosis.

Consistent with the known risks of COVID-19 in people with cancer, half of patients perceived their own risk of COVID-19 to be greater than the general population. Patients also reported wide 
ranging impacts of the pandemic on their emotional wellbeing, finances, employment, family and social life, consistent with trends seen in the general population [23].

Consistent with national guidelines for delivery of cancer care during the COVID-19 pandemic, many patients were monitored remotely through telemedicine [17]. Face to face contact was also significantly reduced through postponement of follow-up appointments and scans where appropriate. Mehta et al. recently reported that interaction with healthcare environments was a prominent source of exposure to SARS-CoV-2 for cancer patients, emphasising the importance of avoiding non-essential visits to the hospital [14].

Treatment interruptions (postponement or cessation) were uncommon for patients in our study, however, these decisions were understandably perceived with uncertainty among some patients undergoing palliative treatment. An international survey of 149 physicians across five continents also reported reductions in all treatments including surgery, radiotherapy and chemotherapy for patients with musculoskeletal tumours [24]. Notably, palliative chemotherapy and radiotherapy were stopped or delayed in $20 \%$ and $17 \%$ of cases, respectively [24]. While the authors concluded that significant harm (pain, morbidity, loss of function) could be caused by delays to care for musculoskeletal tumours such as sarcomas, the true impact in terms of reduction in COVID-19 risk compared to cancer outcome is unknown [24]. Importantly, in our study, the vast majority of patients themselves reported the decision to delay care within the pandemic was a good decision. Follow-up studies are necessary to evaluate longer-term clinical outcomes and patient reported outcomes as it is conceivable that patient symptoms, HRQoL and prognosis may be affected.

Given the rarity and complexity of sarcomas, it is recommended that all patients are managed in a reference centre for sarcomas and/or within reference networks with multidisciplinary expertise $[25,26]$. However, as shown in this study, patients often live a long distance from reference centres. Rapid implementation of telemedicine during the COVID-19 pandemic has given us the opportunity to evaluate the acceptability of remote monitoring, showing that the majority of patients would prefer the incorporation of telemedicine in follow-up. Given the increasing pressures on global healthcare systems, including the National Health Service (NHS) in the UK, telemedicine may be an effective way to manage selected patients [27]. Preference for face to face appointments was associated with lower resilient coping and was more common in patients who did not know their treatment intent. These groups of patients may require more reassurance through face to face appointments. Methods to identify patient and provider preferences are needed to successfully implement telemedicine in routine care.

The prevalence of perceived social isolation in cancer patients is poorly defined, however, previous research and reports suggest it may be experienced by around a quarter of individuals [28]. Social isolation was much higher in our study, with almost half of the participants reporting that they felt isolated. The increased level of perceived isolation is likely a direct result of the COVID-19 pandemic self-isolation recommended by the UK government. A number of researchers have highlighted the negative health effects of social isolation as an unintended consequence of social distancing and the need for mitigation efforts [29-32]. This is particularly important for individuals with cancer where social isolation is associated with a number of clinical and psychosocial outcomes including mortality and HRQoL impairments [33,34].

In our study, $41 \%$ of patients reported that their emotional wellbeing was impacted by the COVID-19 pandemic. Interestingly, EORTC-QLQ-C30 emotional functioning scores were slightly better in patients with sarcoma (curative or palliative intent groups) compared to a normative UK population during a "non-pandemic" period [22]. Although these data are not directly comparable, adaptive coping strategies developed during cancer diagnosis and treatment may enable patients to cope with other adverse situations [35]. Patients that did not know the aim of the treatment had lower emotional functioning, higher worry about COVID-19 and higher insomnia scores. Although these findings could be attributed to uncertainty about the treatment goals, these patients may be a distinct group who require more support. 
Patients who reported palliative intent of treatment/sarcoma management generally had worse HRQoL scores than those treated with curative intent. Unfortunately, EORTC-QLQ-C30 reference values for patients with sarcoma are not available for comparison and we propose repeating HRQoL analysis after the pandemic to determine whether observed trends remain and to evaluate the magnitude of those differences.

There is evidence of widespread anxiety, distress and deterioration in mental health in the general population during the COVID-19 pandemic, and a number of studies have evaluated the impact on cancer patients [36]. A Dutch study compared wellbeing in $>4000$ cancer patients with a matched norm-population without cancer [37]. Quality of life scores were similar; however, cancer patients were more worried about COVID-19 infection while norm-participants were significantly more likely to report depression and loneliness compared to cancer patients [37]. In another survey of breast cancer patients, around half had symptoms of anxiety, depression and insomnia, while $83 \%$ showed symptoms of distress [38]. Frey et al. evaluated the impact of COVID-19 in patients with ovarian cancer [39]. The majority reported significant cancer worry, half had borderline or abnormal anxiety, and a quarter had borderline or abnormal depression [39]. Romito et al. evaluated psychological distress in lymphoma patients and found anxiety and depressive symptoms in around one-third of patients during the pandemic [40]. Using a self-developed COVID-19 questionnaire, Falcone et al. found mean COVID-19 concern of 8/12 (interquartile range $\{\mathrm{IQR}\}$ 5-9) in thyroid cancer patients, which was inversely correlated with EORTC-QLQ-C30 emotional functioning scores [41]. Although these studies used a variety of questionnaires (validated or developed by researchers) and included patients with heterogeneous socio-demographic characteristics, different cancer types and disease stages, they further highlight the unmet need for psychological support in cancer patients during the COVID-19 pandemic and across the disease trajectory [42].

\subsection{Implications for Care}

The COVID-19 pandemic has been a period of great uncertainty. While vaccines are not available and "normality" may be many months away, we need to consider how we can identify and support patients who may be more vulnerable during the pandemic and at other stressful time points during their disease trajectory. Worry about COVID-19 was significantly associated with overall cancer-related worry, irrespective of treatment intent. Higher cancer-related worry was also associated with lower emotional functioning across all treatment intent groups. In clinical practice, screening patients for cancer-related worry may identify patients who require psychological support, both during the pandemic and beyond. Brief screening methods, such as the distress thermometer (patients rate their distress on a scale from 0 to 10), may be useful to recognise patients who may benefit from psychosocial support and enable tailored psychosocial interventions early in their cancer treatment [43]. More detailed assessments such as the Hospital and Anxiety Depression Scale (HADS) and the Brief Symptom Inventory (BSI), may also be suitable for assessing psychological concerns across the disease trajectory [44]. A number of studies have supported the efficacy of psychosocial interventions, which can be provided on an individual, family or group level. Well-established approaches for cancer patients include cognitive-behavioural, existential, and psychodynamic therapies [44]. Referral to specialist psycho-oncology services should be part of the multidisciplinary approach to cancer patient management.

We also found that lower resilient coping score was associated with higher COVID-19 worry in patients treated with curative intent. Patients who had low resilient coping scores were significantly more likely to indicate that they would prefer face to face appointments only; demonstrating that these patients may find personal interaction more reassuring. Resilience and coping are influenced by biological, personal and social factors, and there is substantial evidence that resilience is related to higher cognitive functioning and quality of life, and lower levels of anxiety [45]. We used the four-item Brief Resilient Coping Scale (BRCS) to assess resilient coping in our study. The BRCS has shown internal consistency and validity across several different diseases and populations, and it is short and 
easy to administer [46]. As such, this tool could be used to screen patients in clinical practice who may benefit from additional support during adverse periods; not only the COVID-19 pandemic, but other challenging clinical situations such as recurrence or progression of disease. A number of tailored interventions are available to promote resilience, improve adaptive coping strategies, alleviate distress and promote better HRQoL [47]. For example, the "Promoting Resilience in Stress Management (PRISM)" intervention, focuses on skills to manage stress through cognitive reframing, setting goals and meaning making, and has shown beneficial psychosocial outcomes in adolescents and young adults with cancer [48].

The group of patients who did not know their treatment intent (unknown intent; $n=77$ ) had high worry about COVID-19 and sarcoma, insomnia and were more likely to prefer face to face appointments. Evidence indicates that treatment goals and prognosis are often not discussed due to worry that this information will take away hope or make patients depressed, or because these discussions are emotionally upsetting for clinicians themselves [49]. However, hope can be maintained through setting realistic goals, even in the setting of incurable disease [50]. Early discussions about treatment goals in the context of patient values may help to guide management decisions including timely advance care planning. Uncertainty about treatment intent in sarcoma patients requires further study.

Loneliness was associated with living alone and not having a partner. Social isolation during self-isolation when living alone is complex and these patients may be at higher risk for adverse psychosocial outcomes [29]. Loneliness was also more common among adolescents and young adults (aged 16-39 years) and middle-aged patients (aged 40-64 years). Previous studies have described loneliness and isolation among adolescents and young adults with cancer, resulting from disruption to normal developmental challenges and feeling "different" to peers [51]. Interventions that have shown promise in reducing loneliness include those focused on enhancing social skills, providing social support, facilitating opportunities for social contact and addressing maladaptive social cognition; the latter appears to be the most effective strategy [52]. The challenge is to introduce safe interventions that can support vulnerable patients and adhere to national guidelines on social distancing. Technology has been vitally important for the delivery of care during this pandemic and support could be provided through existing digital health innovations [53]. Others have tested innovative methods during the pandemic, such as a Whatsapp messaging system for resolving queries during the COVID-19 pandemic [54]. Alternative approaches must be considered for people without access to the internet. Signposting patients to accurate information will also be important, including advice about boosting wellbeing through physical activity and nutritional support.

\subsection{Limitations}

Participants in this survey were mostly White and well-educated. It would be interesting to assess the views of patients from a wider range of educational backgrounds, and also evaluate the experiences of patients from Black, Asian, and minority ethnic backgrounds; a group at particularly high risk of complications due to COVID-19. Translation of surveys and the use of other qualitative methods, such as interviews, could also be considered for future studies. Patients self-reported their treatment intent; however, previous studies have shown significant discordance between patient expectations of treatment intent [55]. As the survey was anonymous, we did not link survey responses with clinical data and therefore verification of treatment intent was not possible. The UK has a publicly-funded National Health Service (NHS), and therefore these data may not be generalizable to other countries where socioeconomic and demographic factors influence access to healthcare; such disparities may be further exaggerated during the pandemic due to variability in financial support offered by governments, public health guidance and cancer care infrastructure. 


\section{Materials and Methods}

This study was a cross-sectional survey assessing the experiences of sarcoma patients at two of the largest specialist sarcoma centres in Europe, the Royal Marsden NHS Foundation Trust (RMH) and the University College London Hospitals NHS Foundation Trust (UCLH, London Sarcoma Service).

\subsection{Participants}

We identified patients aged $\geq 16$ years with a diagnosis of sarcoma (soft tissue sarcomas, bone sarcomas and gastrointestinal stromal tumours (GIST)), who had a planned outpatient appointment between 23 March and 23 May 2020 in the Medical Oncology and Radiation Oncology departments of the Sarcoma Units at RMH and UCLH. Patients with benign tumours, including desmoid fibromatosis, that were unable to communicate in English or too unwell, were not eligible.

Eligible patients at RMH consented by phone to receive the anonymous survey (online or paper version). Eligible patients at UCLH were invited by phone or sent an email with the survey details. The survey was administered through SurveyMonkey; whose security has been established in accordance with international standards [56]. Data collection was completed 30 May 2020.

\subsection{Measures}

The survey for this study was designed by sarcoma clinicians, an epidemiology and HRQoL expert (O.H.), a patient advocate (R.W.) and the patient and public involvement panel (PPI) of the RMH (Appendix B). The survey included a combination of validated questionnaires and items developed for this study. Questions developed for this survey included socio-demographic items, sarcoma management items, worry about COVID-19, psychosocial impact of the COVID-19 pandemic, and care experiences during the pandemic. Further details and preliminary results of the telemedicine section have been published elsewhere [27].

HRQoL was assessed using the European Organization for the Research and Treatment of Cancer Quality of Life Questionnaire (EORTC-QLQ-C30) functioning scales (physical, cognitive, social, role and emotional functioning), global health status/QoL items, and the insomnia item. HRQoL were analysed using EORTC scoring guidelines, all of the scales and single-item measures range in score from 0 to 100 [57]. High scores on the scales and global HRQoL items represent high functioning or HRQoL. A high score on the insomnia item represents worse insomnia.

The UCLA (University of California, Los Angeles) abbreviated Loneliness Scale was used to assess loneliness [58]. The sum of responses to the three items of this scale indicates whether respondents are lonely (scores 6-9) or not lonely (scores 3-5). The ability to cope with stress was assessed using the Brief Resilient Coping Scale (BRCS) [46]. Summed scores correspond to "low resilient copers" (4-13 points), "medium resilient copers" (14-16) and "high resilient copers" (17-20) [45].

\subsection{Statistical Analysis}

SPSS statistics version 25 was used for the analysis. Missing responses were not included, and only available data were analysed. The online survey was programmed to ensure that all EORTC-QLQ-C30 questions were answered before responses could be submitted. Descriptive statistics were used to summarise results; frequencies and percentages for categorical items, mean and standard deviation (SD) for continuous items.

We anticipated that the COVID-19 pandemic would have a different impact on patients undergoing treatment with palliative intent compared to curative intent, and therefore stratified responses according to self-reported treatment intent (curative vs. palliative). In order to assess overall worry about sarcoma and COVID-19, we further stratified patients receiving active treatment versus those not receiving active treatment. We also included the group of patients who did not know the aim of their treatment or management as the "unknown intent" group. As EORTC-QLQ-C30 sarcoma patient 
reference values are not available, we included UK normative population values for comparison with HRQoL data (non-pandemic) [22].

We used Chi-squared tests to evaluate differences between categorical variables (Fisher's exact test where cell values were $\leq 5$ ). ANOVA was used to assess differences in the means between treatment groups (curative, palliative or unknown intent), including age, sarcoma worry, COVID-19 worry and HRQoL scores. We used multivariate linear regression to assess associations between patient characteristics, care modifications, psychosocial impact of pandemic, HRQoL domains, worry about COVID-19 and worry about sarcoma in each treatment group (curative/palliative/unknown intent) separately. Factors significantly associated with the independent and dependent variable in univariate analysis at the $p \leq 0.100$ level were included in the models. $p$-values of $\leq 0.05$ were considered statistically significant.

\subsection{Ethical approval}

Ethical approval was obtained at the RMH from the Committee for Clinical Review (SE939). Ethical approval was not required at UCLH for this survey. Anonymous survey responses from patients recruited at RMH and UCLH were combined for the final analysis. All participants gave informed consent prior to completing the survey. All data were handled in accordance with the Declaration of Helsinki.

\section{Conclusions}

Postponement of care and the use of telemedicine to replace face to face appointments were generally perceived positively, however, the longer-term clinical consequences are not yet known. Worry about potential impact of COVID-19 on personal health was moderately high and was strongly related to the level of worry about cancer and resilient coping. Emotional functioning was significantly lower in patients with high cancer-related worry, irrespective of treatment intent. Patients with high cancer-related worry or low resilience may benefit from tailored psychological support across their disease trajectory, in order to promote coping during other adverse (clinical) situations. Patients who were uncertain about their treatment intent appeared to be a distinct group with high COVID-19 worry, high insomnia and low emotional functioning. Discussions about treatment goals, which consider information preferences and beliefs, may reduce uncertainty and improve HRQoL in these patients. In view of global changes to the delivery of cancer care during the COVID-19 pandemic, our findings are of relevance to the wider cancer population. Further studies are needed to assess the longer-term impact of the pandemic on HRQoL in patients with cancer.

Author Contributions: Conceptualisation, E.Y., A.S., E.L., R.W., P.D., S.G., O.H. and R.L.J.; Data curation, E.Y. and A.S.; Formal analysis, E.Y., E.L. and O.H.; Investigation, A.S., S.F., K.I., N.C., A.M. (Alessandra Maleddu), Y.A., E.M., C.B., A.M. (Aisha Miah), S.Z., A.M. (Anne McTiernan)., S.J.S. and P.D.; Methodology, E.Y., E.L., R.W., S.G., O.H. and R.L.J.; Supervision, O.H. and R.L.J.; Validation, O.H.; Writing—original draft, E.Y., A.S., E.L., S.F., K.I., N.C., A.M. (Alessandra Maleddu), Y.A., E.M., R.W., C.B., A.M. (Aisha Miah), S.Z., A.M. (Anne McTiernan)., S.J.S., P.D., S.G., O.H. and R.L.J.; Writing-review and editing, E.Y., A.S., E.L., S.F., K.I., N.C., A.M., E.M., R.W., C.B., A.M., S.Z., A.M., S.J.S., P.D., S.G., O.H. and R.L.J. All authors have read and agreed to the published version of the manuscript.

Funding: This research received no external funding. The work was undertaken in the Royal Marsden NHS Foundation Trust together with the Institute of Cancer Research which receives Biomedical Research Centre (BRC) funding through the National Institute for Health Research (NIHR).

Acknowledgments: We would like to thank Milou Reevers for programming the online survey and Aislinn Macklin-Doherty for inviting patients.

Conflicts of Interest: R.L.J. is the recipient of grants/research support from MSD, GSK. R.L.J. is the recipient of consultation fees from Adaptimmune, Athenex, Blueprint, Clinigen, Eisai, Epizyme, Daichii, Deciphera, Immunedesign, Lilly Merck, Pharmamar, UptoDate. R.W. is a director for Sarcoma Patients Euronet E.v. All other authors have no conflicts of interests to declare. 


\section{Appendix A. Patient Recruitment}

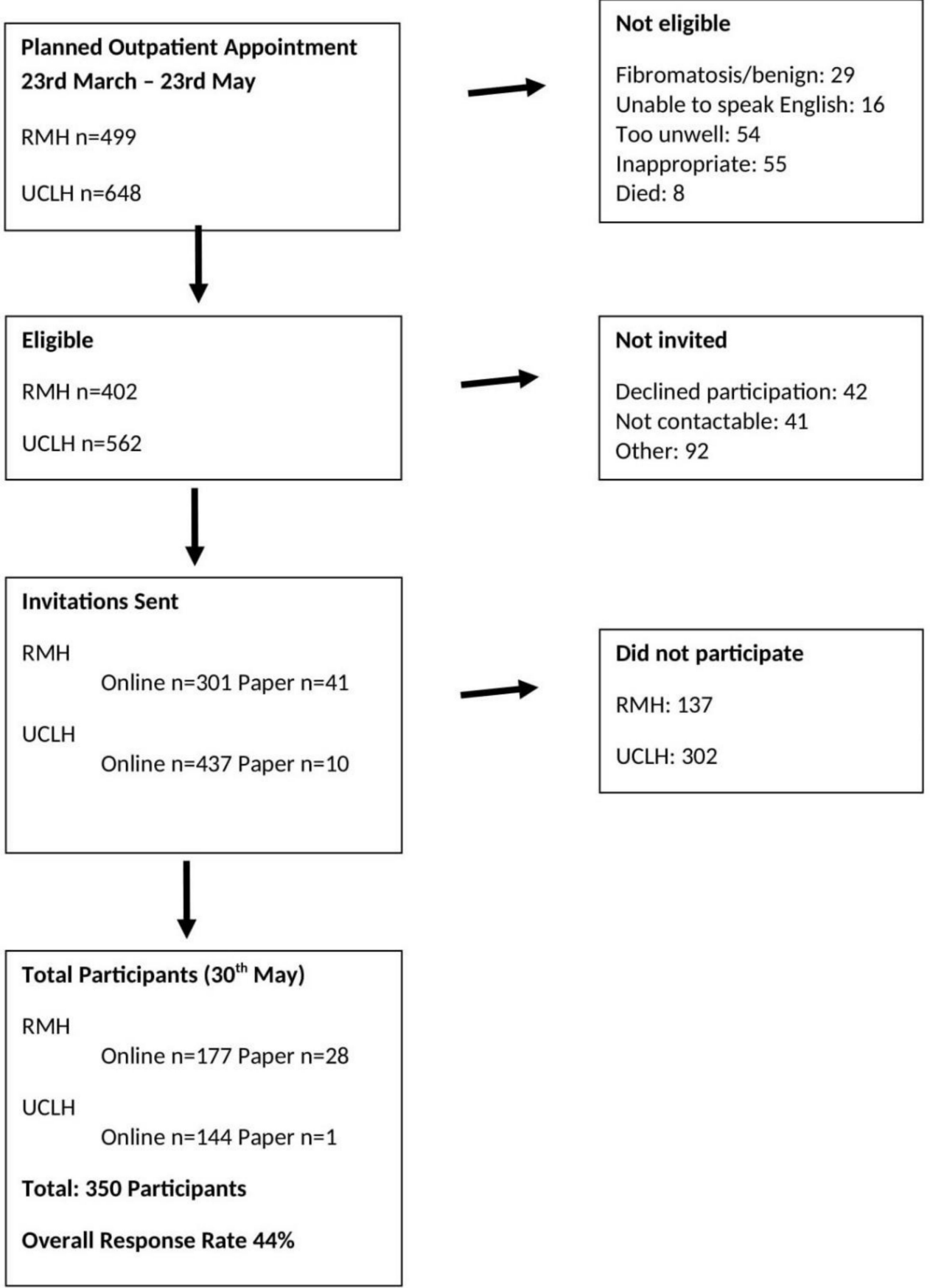

Figure A1. Flow chart of patient recruitment.

\section{Appendix B. Questionnaire}

Sarcoma Patient Experience during COVID-19 Pandemic

Questionnaire

Instructions:

Thank you for volunteering to take part in this survey to help us to understand more about the experiences of patients with sarcoma during the coronavirus (COVID-19) pandemic. Please attempt 
to answer all of the questions. Please choose the answer option that is most applicable to your own situation. In this survey we will use the term 'COVID-19' to refer to the disease causing the current pandemic and refer to the 'COVID-19 pandemic' where appropriate.

Section 1: About you

1. How old are you?

....... years

2. What is your gender?

Male

Female

Other, please specify

3. What is your ethnicity?

European/Caucasian

Asian

Black

Mixed

Other, please specify

4. What is your current living situation? (Please check all that apply)

I live alone

I live with my spouse/partner

I live with children in the home

I live with friend(s) or roommate(s) who are not related to me (e.g., students or lodgers)

I live with my parent(s)

Other, please specify

5. What is your marital status?

Married/in a relationship

Divorced

Widowed

Single

6. What is your highest level of education?

None/Primary school

Secondary school

College/diploma/vocational qualification

University/postgraduate degree

7. Do you have any of the following medical conditions? (please tick all that apply)

Chronic Obstructive Pulmonary Disease (COPD)

Hypertension (high blood pressure)

Diabetes

Coronary artery disease/heart disease (e.g., previous heart attack)

Obesity

None of the above

8. How long is your usual journey time from your home to the Royal Marsden Hospital?

Less than $1 \mathrm{~h}$ journey time

More than $1 \mathrm{~h}$ journey time

9. How do you usually travel to the Royal Marsden Hospital? (please tick all that apply)

I walk

Bus

Train

Underground 
Car

Other, please specify

\section{Section 2: COVID-19}

1. On a scale of 1 to 10, please rate your current level of worry about the impact of COVID-19 on your health. (1—not worried at all, 10—extremely worried).

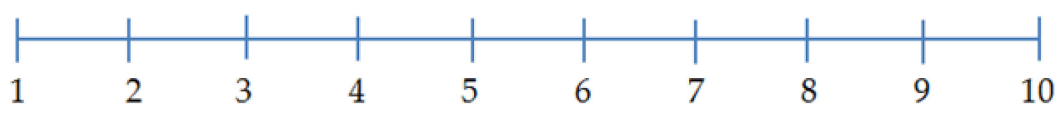

(no worry)

(extremely worried)

2. Do you think you are at higher risk of contracting COVID-19 than others in the population:

Yes, higher risk

Equal, same risk

No, lower risk

Don't know

3. Do you think you have had COVID-19?

Yes, confirmed with swab (test)

Yes, I think I had symptoms of the COVID-19, but have not had a test to confirm

Yes, I think I had symptoms of COVID-19, but I had a negative test

No, I have not had symptoms of COVID-19

I don't know

4. Has the COVID-19 pandemic had an impact on any of the following? (please tick all that apply)

Employment

Financial situation

Family life

Emotional wellbeing

Social life/activities

Other, please specify

5. In the next 12 months, if you developed a life threatening respiratory disease (due to COVID-19 or other cause), do you think you would accept treatment with a ventilator (a machine to breathe for you)?

Yes

No

I don't know.

Section 3: Sarcoma

1. On a scale of 1 to 10 , please rate your current level of worry about your sarcoma? (1-not worried at all, 10—extremely worried)

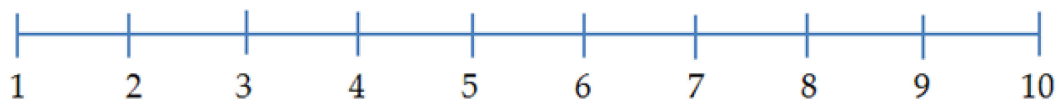

(no worry)

(extremely worried)

2. Are you currently having treatment for sarcoma?

Yes, intravenous (through a vein) anticancer treatment given at the hospital

Yes, oral (tablets) anticancer treatments 
Yes, radiotherapy

Yes, other treatment for sarcoma (please specify)

No, I am not receiving treatment.

I don't know.

3. Are you currently taking part in a clinical trial (i.e., research study)?

Yes, I am currently receiving treatment as part of a clinical trial

No, I was taking part in a trial but my participation was paused due to COVID-19 pandemic

No, I was taking part in a clinical trial but my participation was stopped due to COVID-19 pandemic

No, I was being considered for a clinical trial but this was put on hold due to COVID-19 pandemic No, I am not taking part in a clinical trial.

4. What is the aim of your current treatment or management plan (including surveillance or monitoring with scans)?

Curative (cure of disease) or I have no evidence of sarcoma

Palliative (control of disease)

I do not know.

5. Over the last year, what was the usual frequency of your follow-up appointments with the sarcoma team?

Intervals of less than three months (e.g., every few weeks)

Three or four month interval

Six month intervals

Annual

Other, please specify

Section 4: Telemedicine

1. Have you had an appointment with the sarcoma team at the Royal Marsden Hospital since 23 March 2020?

Yes, I have had a face to face appointment at the Royal Marsden Hospital.

Yes, I have had a telephone appointment with a doctor from the Royal Marsden Hospital.

Yes, other e.g., video consultation

No, I have not had an appointment

I don't know

2. If you have had a face to face appointment with a doctor in the hospital since 23 March 2020, how satisfied were you with the consultation? (Please select a number on the scale from 1-10: $1=$ not satisfied at all and $10=$ extremely satisfied). If you have not had a face to face appointment during this period, please tick not applicable.

Not applicable

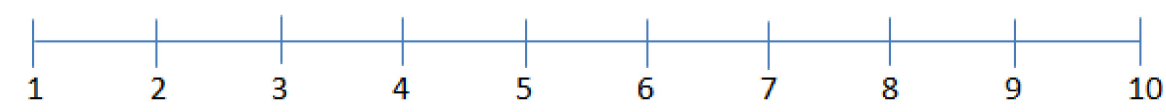

(not satisfied at all)

(extremely satisfied)

3. If you have had a telephone appointment with a doctor since 23 March 2020, how satisfied where you with the consultation? (Please select a number on the scale from 1-10: $1=$ not satisfied at all and $10=$ extremely satisfied). If you have not had a telephone appointment during this period, please tick not applicable.

Not applicable 


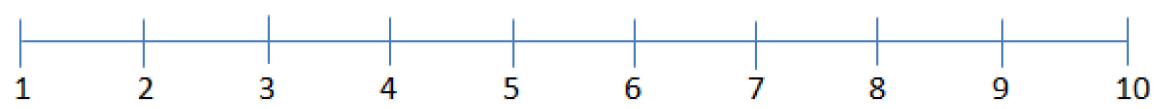

(not satisfied at all)

(extremely satisfied)

4. If you had a video appointment (e.g., Zoom/Skype) with a doctor since 23 March 2020, how satisfied where you with the consultation? (Please select a number on the scale from 1-10: $1=$ not satisfied at all and $10=$ extremely satisfied). If you have not had a video appointment during this period, please tick not applicable.

Not applicable

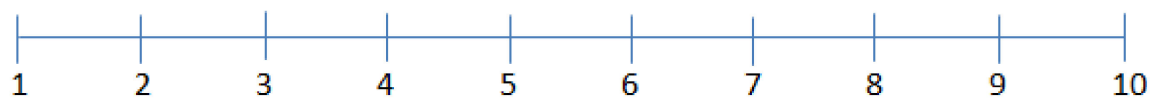

(not satisfied at all)

(extremely satisfied)

5. I had previously met the doctor who performed my telemedicine appointment.

Yes

No

I don't know

Not applicable

6. If you had a choice for your future routine appointments:

(a) Which type of consultation would you prefer? (please choose one option) Face to face appointments only

Mostly face to face appointments, occasional telemedicine

Mostly telemedicine appointments, occasional face to face appointments

Only telemedicine appointments

I don't know.

(b) What are the main reasons that you chose this option? (please select all that apply)

Reduced time travelling to the hospital

Reduced cost of travelling to the hospital

Reduced waiting in the hospital

I would find it more reassuring

I think my treatment plan would be clearer

I think it is more convenient

Other, please specify

7. If telemedicine (phone or video) was an option for patient care at the Royal Marsden Hospital moving forward, I would prefer using the following method: (please select one option)

Telephone

Video call (such as Zoom, or Skype)

8. I would not wish to hear the following information by a telemedicine (phone or video) appointment (please select all that apply)

Any results of imaging tests (CT scan or MRI results)

Bad news from imaging tests (i.e., growth of cancer on CT or MRI test, new area of cancer seen on imaging test)

Blood test results

Results from a team discussion regarding my care (for example, whether the team recommended to continue with my current treatment or suggested that I need to see a surgeon to manage my cancer) 
9. Do you think having a specialist nurse in sarcoma participate in the telemedicine (phone or video) appointment would be useful?

Always

Sometimes-for example when the doctor is telling me bad news (like CT scan showing cancer is growing or new areas of cancer)

Sometimes-I would like the option of asking for a nurse to be present during my telemedicine appointment

Never

I don't know

Section 5: Experiences of Care

1. Have your follow-up appointments been postponed due to the COVID-19 pandemic?

No, my follow-up has not changed

Yes, postponed for up to three months.

Yes, postponed for more than three months

I don't know

2. If your follow-up appointments have been postponed, what are your views on that decision?

I think it was a good decision

I think it was a bad decision

I am not sure whether it was a good or bad decision.

Not applicable, my appointments have not been changed.

3. Have your scans been postponed due to due to the COVID-19 pandemic?

No, my routine scans have not changed

Yes, postponed for up to three months.

Yes, postponed for more than three months

Not applicable, I do not have scans

I don't know

4. If your scanshave been postponed, what are your views on that decision?

I think it was a good decision

I think it was a bad decision

I am not sure whether it was a good or bad decision.

Not applicable (my routine scans have not been changed, or I do not have scans)

5. Has your treatment been postponed or discontinued due to the COVID-19 pandemic?

No, my treatment has continued as normal

Yes, postponed for up to three months

Yes, $\overline{\text { postponed }}$ for more than three months

Yes, my current treatment has been discontinued

Not applicable, I am not on treatment

I don't know

6. If your treatment has been postponed or discontinued, what are your views on that decision?

I think it was a good decision

I think it was a bad decision

I am not sure whether it was a good or bad decision.

Not applicable, my treatment has not been postponed

Not applicable, I am not on treatment.

7. Are you concerned about the quality of your care during the COVID-19 pandemic

My care has not been affected

The pandemic has had a negative impact on my care

The pandemic has had a positive impact on my care

I don't know 
8. Do you feel informed about the plan for your follow-up (and treatment if applicable)?

Yes, very well informed

Yes, informed

I received very little information

Not informed at all

Section 5: Health-related Quality of life

1. We are interested in some things about you and your health. Please answer all of the questions yourself by choosing the option that best applies to you. There are no "right" or "wrong" answers.

\begin{tabular}{|c|c|c|c|c|}
\hline & Not at All & A Little & Quite a Bit & Very Much \\
\hline \multicolumn{5}{|l|}{$\begin{array}{c}\text { Do you have any trouble doing strenuous activities like } \\
\text { carrying a heavy shopping bag or a suitcase? }\end{array}$} \\
\hline \multicolumn{5}{|l|}{ Do you have any trouble taking a long walk? } \\
\hline \multicolumn{5}{|l|}{$\begin{array}{l}\text { Do you have any trouble taking a short walk outside of } \\
\text { the house? }\end{array}$} \\
\hline \multicolumn{5}{|l|}{ Do you need to stay in bed or a chair during the day? } \\
\hline \multicolumn{5}{|l|}{$\begin{array}{l}\text { Do you need help with eating, dressing, washing yourself } \\
\text { or using the toilet? }\end{array}$} \\
\hline \multicolumn{5}{|l|}{ During the past week: } \\
\hline \multicolumn{5}{|l|}{$\begin{array}{l}\text { Were you limited in doing either your work or other } \\
\text { daily activities? }\end{array}$} \\
\hline \multicolumn{5}{|l|}{$\begin{array}{l}\text { Were you limited in pursuing your hobbies or other } \\
\text { leisure time activities? }\end{array}$} \\
\hline \multicolumn{5}{|l|}{ Have you had trouble sleeping? } \\
\hline \multicolumn{5}{|l|}{$\begin{array}{l}\text { Have you had difficulty in concentrating on things, } \\
\text { like reading a newspaper or watching television? }\end{array}$} \\
\hline \multicolumn{5}{|l|}{ Did you feel tense? } \\
\hline \multicolumn{5}{|l|}{ Did you worry? } \\
\hline \multicolumn{5}{|l|}{ Did you feel irritable? } \\
\hline \multicolumn{5}{|l|}{ Did you feel depressed? } \\
\hline \multicolumn{5}{|l|}{ Have you had difficulty remembering things? } \\
\hline \multicolumn{5}{|l|}{$\begin{array}{l}\text { Has your physical condition or medical treatment } \\
\text { interfered with your family life? }\end{array}$} \\
\hline $\begin{array}{l}\text { Has your physical condition or medical treatment } \\
\text { interfered with your social activities? }\end{array}$ & & & & \\
\hline
\end{tabular}

For the following two questions, please choose the number between 1 and 7 that best applies to you.

2. How would you rate your overall health during the past week?
${ }_{1} \square$
${ }_{2} \square$
${ }_{3}$
${ }_{4} \square$
${ }_{5} \square$
$6 \square$
$7 \square$
Very poor
Excellent

3. How would you rate your overall quality of life during the past week? 
${ }_{1} \square$

Very poor
2
${ }_{4} \square$
5
$6 \square$
7

Excellent

Section 6: Support and coping

The next three questions are about how you feel about different aspects of your life. For each one, indicate how often you have felt that way over the past week.

1. How often do you feel that you lack companionship?

Hardly ever

Some of the time

Often

2. How often do you feel left out?

Hardly ever

Some of the time

Often

3. How often do you feel isolated from others?

Hardly ever

Some of the time

Often

4. Who would you choose to contact for any problems related to your sarcoma, or questions about your cancer care during the COVID-19 pandemic? (please tick all that apply)

Sarcoma clinical nurse specialist

Royal Marsden Hospital helpline

General practitioner (GP)

Sarcoma charity (e.g., Sarcoma UK, BCRT)

Other cancer charity (e.g., Macmillan, Cancer Research UK)

Online peer support groups

NHS helpline (111)

Other, please specify

5. Do you feel comfortable contacting your healthcare providers (GP or sarcoma team) during the

COVID-19 pandemic?

I feel able to contact my healthcare providers as normal

I am worried about availability of healthcare providers

I would try not to contact healthcare providers unless absolutely essential

I don't know

6. Consider how well the following statements describe your usual behaviour and actions:

\begin{tabular}{|c|c|c|c|c|c|}
\hline & $\begin{array}{c}\text { (1) Does not } \\
\text { describe me at all }\end{array}$ & $\begin{array}{l}\text { (2) Does not } \\
\text { describe me }\end{array}$ & (3) Neutral & $\begin{array}{l}\text { (4) Describes } \\
\text { me }\end{array}$ & $\begin{array}{l}\text { (5) Describes } \\
\text { me very well. }\end{array}$ \\
\hline \multicolumn{6}{|l|}{$\begin{array}{l}\text { I look for creative ways to alter } \\
\text { difficult situations }\end{array}$} \\
\hline \multicolumn{6}{|l|}{$\begin{array}{l}\text { Regardless of what happens to } \\
\text { me, I believe I can control my } \\
\text { reaction to it. }\end{array}$} \\
\hline \multicolumn{6}{|l|}{$\begin{array}{c}\text { I believe I can grow in positive } \\
\text { ways by dealing with difficult } \\
\text { situations }\end{array}$} \\
\hline $\begin{array}{l}\text { I actively look for ways to replace } \\
\text { the losses I encounter in life. }\end{array}$ & & & & & \\
\hline
\end{tabular}


Please use the space below to add any further comments:

\section{References}

1. Zhou, F.; Yu, T.; Du, R.; Fan, G.; Liu, Y.; Liu, Z.; Xiang, J.; Wang, Y.; Song, B.; Gu, X.; et al. Clinical course and risk factors for mortality of adult inpatients with COVID-19 in Wuhan, China: A retrospective cohort study. Lancet 2020, 395, 1054-1062. [CrossRef]

2. World Health Organisation: Coronavirus Disease (COVID19) Pandemic Statistics. Available online: https://www.who.int/emergencies/diseases/novel-coronavirus-2019 (accessed on 1 June 2020).

3. Prem, K.; Liu, Y.; Russell, T.W.; Kucharski, A.J.; Eggo, R.M.; Davies, N.; Jit, M.; Klepac, P.; Flasche, S.; Clifford, S.; et al. The effect of control strategies to reduce social mixing on outcomes of the COVID-19 epidemic in Wuhan, China: A modelling study. Lancet Public Health 2020, 5, e261-e270. [CrossRef]

4. Wilder-Smith, A.; Freedman, D.O. Isolation, quarantine, social distancing and community containment: Pivotal role for old-style public health measures in the novel coronavirus (2019-nCoV) outbreak. J. Travel Med. 2020, 27, taaa020. [CrossRef] [PubMed]

5. The Rt Hon Boris Johnson MP. Statement on Coronavirus 23rd March 2020. Available online: https: //www.gov.uk/government/speeches/pm-address-to-the-nation-on-coronavirus-23-march-2020 (accessed on 8 June 2020).

6. World Health Organisation. Report of the WHO-China Joint Mission on Coronavirus Disease 2019 (COVID-19). Available online: https:/www.who.int/publications-detail/report-of-the-who-china-jointmission-on-coronavirus-disease-2019-(covid-19) (accessed on 8 June 2020).

7. Wang, D.; Hu, B.; Hu, C.; Zhu, F.; Liu, X.; Zhang, J.; Wang, B.; Xiang, H.; Cheng, Z.; Xiong, Y.; et al. Clinical Characteristics of 138 Hospitalized Patients With 2019 Novel Coronavirus-Infected Pneumonia in Wuhan, China. JAMA 2020, 323, 1061. [CrossRef] [PubMed]

8. Guan, W.-J.; Ni, Z.-Y.; Hu, Y.; Liang, W.-H.; Ou, C.-Q.; He, J.-X.; Liu, L.; Shan, H.; Lei, C.-L.; Hui, D.S.; et al. Clinical Characteristics of Coronavirus Disease 2019 in China. New Engl. J. Med. 2020, 382, 1708-1720. [CrossRef] [PubMed]

9. Chen, N.; Zhou, M.; Dong, X.; Qu, J.; Gong, F.; Han, Y.; Qiu, Y.; Wang, J.; Liu, Y.; Wei, Y.; et al. Epidemiological and clinical characteristics of 99 cases of 2019 novel coronavirus pneumonia in Wuhan, China: A descriptive study. Lancet 2020, 395, 507-513. [CrossRef]

10. Verity, R.; Okell, L.C.; Dorigatti, I.; Winskill, P.; Whittaker, C.; Imai, N.; Cuomo-Dannenburg, G.; Thompson, H.; Walker, P.G.T.; Fu, H.; et al. Estimates of the severity of coronavirus disease 2019: A model-based analysis. Lancet Infect. Dis. 2020, 20, 669-677. [CrossRef]

11. The OpenSAFELY Collaborative; Williamson, E.; Walker, A.J.; Bhaskaran, K.; Bacon, S.; Bates, C.; Morton, C.E.; Curtis, H.; Mehrkar, A.; Evans, D.; et al. OpenSAFELY: Factors associated with COVID-19-related hospital death in the linked electronic health records of 17 million adult NHS patients. Available online: https: //doi.org/10.1101/2020.05.06.20092999 (accessed on 12 August 2020).

12. Wu, Z.; McGoogan, J.M. Characteristics of and Important Lessons from the Coronavirus Disease 2019 (COVID-19) Outbreak in China. JAMA 2020, 323, 1239. [CrossRef]

13. Liang, W.; Guan, W.; Chen, R.; Wang, W.; Li, J.; Xu, K.; Li, C.; Ai, Q.; Lu, W.; Liang, H.; et al. Cancer patients in SARS-CoV-2 infection: A nationwide analysis in China. Lancet Oncol. 2020, 21, 335-337. [CrossRef] 
14. Mehta, V.; Goel, S.; Kabarriti, R.; Cole, D.; Goldfinger, M.; Acuna-Villaorduna, A.; Pradhan, K.; Thota, R.; Reissman, S.; Sparano, J.A.; et al. Case Fatality Rate of Cancer Patients with COVID-19 in a New York Hospital System. Cancer Discov. 2020, 10, 935-941. [CrossRef]

15. Onder, G.; Rezza, G.; Brusaferro, S. Case-Fatality Rate and Characteristics of Patients Dying in Relation to COVID-19 in Italy. JAMA 2020, 323, 1775-1776. [CrossRef]

16. Rogado, J.; Obispo, B.; Pangua, C.; Serrano-Montero, G.; Marino, A.M.; Pérez-Pérez, M.; López-Alfonso, A.; Gullón, P.; Lara, M.Á. Covid-19 transmission, outcome and associated risk factors in cancer patients at the first month of the pandemic in a Spanish hospital in Madrid. Clin. Transl. Oncol. 2020, 1-5. [CrossRef]

17. National Institute for Clinical Excellence. COVID-19 Rapid Guideline: Delivery of Systemic Anticancer Treatments (NG161). Available online: https://www.nice.org.uk/guidance/ng161 (accessed on 8 June 2020).

18. Büntzel, J.; Klein, M.; Keinki, C.; Walter, S.; Büntzel, J.; Hübner, J. Oncology services in corona times: A flash interview among German cancer patients and their physicians. J. Cancer Res. Clin. Oncol. 2020, 1-3. [CrossRef]

19. Qiu, J.; Shen, B.; Zhao, M.; Wang, Z.; Xie, B.; Xu, Y.-F. A nationwide survey of psychological distress among Chinese people in the COVID-19 epidemic: Implications and policy recommendations. Gen. Psychiatry 2020, 33, e100213. [CrossRef] [PubMed]

20. Mazza, C.; Ricci, E.; Biondi, S.; Colasanti, M.; Ferracuti, S.; Napoli, C.; Roma, P. A Nationwide Survey of Psychological Distress among Italian People during the COVID-19 Pandemic: Immediate Psychological Responses and Associated Factors. Int. J. Environ. Res. Public Health 2020, 17, 3165. [CrossRef] [PubMed]

21. Shuja, K.H.; Aqeel, M.; Jaffar, A.; Ahmed, A. COVID-19 Pandemic and Impending Global Mental Health Implications. Psychiatr. Danub. 2020, 32, 32-35. [CrossRef]

22. Nolte, S.; Liegl, G.; Petersen, M.; Aaronson, N.K.; Costantini, A.; Fayers, P.; Groenvold, M.; Holzner, B.; Johnson, C.; Kemmler, G.; et al. General population normative data for the EORTC QLQ-C30 health-related quality of life questionnaire based on 15,386 persons across 13 European countries, Canada and the Unites States. Eur. J. Cancer 2019, 107, 153-163. [CrossRef]

23. Torales, J.; O'Higgins, M.; Castaldelli-Maia, J.M.; Ventriglio, A. The outbreak of COVID-19 coronavirus and its impact on global mental health. Int. J. Soc. Psychiatry 2020, 66, 317-320. [CrossRef]

24. Thaler, M.; Khosravi, I.; Leithner, A.; Papagelopoulos, P.J.; Ruggieri, P. Impact of the COVID-19 pandemic on patients suffering from musculoskeletal tumours. Int. Orthop. 2020, 44, 1503-1509. [CrossRef]

25. Casali, P.; Abecassis, N.; Bauer, S.; Biagini, R.; Bielack, S.; Bonvalot, S.; Boukovinas, I.; Bovee, J.V.M.G.; Brodowicz, T.; Broto, J.; et al. Soft tissue and visceral sarcomas: ESMO-EURACAN Clinical Practice Guidelines for diagnosis, treatment and follow-up. Ann. Oncol. 2018, 29, iv51-iv67. [CrossRef]

26. Casali, P.G.; Bielack, S.; Abecassis, N.; Aro, H.T.; Bauer, S.; Biagini, R.; Bonvalot, S.; Boukovinas, I.; Bovee, J.V.M.G.; Brennan, B.; et al. Bone sarcomas: ESMO-PaedCan-EURACAN Clinical Practice Guidelines for diagnosis, treatment and follow-up. Ann. Oncol. 2018, 29, iv79-iv95. [CrossRef] [PubMed]

27. Smrke, A.; Younger, E.; Wilson, R.; Husson, O.; Farag, S.; Merry, E.; Macklin-Doherty, A.; Cojocaru, E.; Arthur, A.; Benson, C.; et al. Telemedicine During the COVID-19 Pandemic: Impact on Care for Rare Cancers. JCO Glob. Oncol. 2020, 6, 1046-1051. [CrossRef]

28. Ernst, J.; Mehnert-Theuerkauf, A.; Dietz, A.; Hornemann, B.; Esser, P. Perceived stigmatization and its impact on quality of life-results from a large register-based study including breast, colon, prostate and lung cancer patients. BMC Cancer 2017, 17, 741. [CrossRef]

29. A Holmes, E.; O'Connor, R.C.; Perry, V.H.; Tracey, I.; Wessely, S.; Arseneault, L.; Ballard, C.; Christensen, H.; Silver, R.C.; Everall, I.; et al. Multidisciplinary research priorities for the COVID-19 pandemic: A call for action for mental health science. Lancet Psychiatry 2020, 7, 547-560. [CrossRef]

30. Wang, C.; Pan, R.; Wan, X.; Tan, Y.; Xu, L.; Ho, C.S.H.; Ho, R.C.M. Immediate Psychological Responses and Associated Factors during the Initial Stage of the 2019 Coronavirus Disease (COVID-19) Epidemic among the General Population in China. Int. J. Environ. Res. Public Health 2020, 17, 1729. [CrossRef] [PubMed]

31. Zhang, Y.; Ma, Z.F. Impact of the COVID-19 Pandemic on Mental Health and Quality of Life among Local Residents in Liaoning Province, China: A Cross-Sectional Study. Int. J. Environ. Res. Public Health 2020, 17, 2381. [CrossRef]

32. Armitage, R.; Nellums, L.B. COVID-19 and the consequences of isolating the elderly. Lancet Public Health 2020, 5, e256. [CrossRef] 
33. Kroenke, C.; Kubzansky, L.D.; Schernhammer, E.; Holmes, M.D.; Kawachi, I. Social Networks, Social Support, and Survival After Breast Cancer Diagnosis. J. Clin. Oncol. 2006, 24, 1105-1111. [CrossRef]

34. Nausheen, B.; Carr, N.J.; Peveler, R.C.; Moss-Morris, R.; Verrill, C.; Robbins, E.; Nugent, K.; Baker, A.M.; Judd, M.; Gidron, Y. Relationship between Loneliness and Proangiogenic Cytokines in Newly Diagnosed Tumors of Colon and Rectum. Psychosom. Med. 2010, 72, 912-916. [CrossRef]

35. Nipp, R.D.; El-Jawahri, A.; Fishbein, J.N.; Eusebio, J.; Stagl, J.M.; Gallagher, E.R.; Park, E.R.; Jackson, V.A.; Pirl, W.F.; Greer, J.A.; et al. The relationship between coping strategies, quality of life, and mood in patients with incurable cancer. Cancer 2016, 122, 2110-2116. [CrossRef]

36. Vindegaard, N.; Benros, M.E. COVID-19 pandemic and mental health consequences: Systematic review of the current evidence. Brain Behav. Immun. 2020, 0889. [CrossRef] [PubMed]

37. Van de Poll-Franse, L.V.; de Rooij, B.H.; Horevoorts, N.J.E.; May, A.M.; Vink, G.R.; Koopman, M.; van Laarhoven, H.W.M.; Besselink, M.G.; Oerlemans, S.; Husson, O.; et al. The impact of the COVID-19 crisis on perceived changes in care and wellbeing of cancer patients and norm participants: Results of the PROFILES registry. In Proceedings of the European Society Medical Oncology Conference, 19-21 July 2020; Abstract 3203.

38. Juanjuan, L.; Santa-Maria, C.A.; Hongfang, F.; Lingcheng, W.; Pengcheng, Z.; Yuangbing, X.; Yuyan, T.; Zhongchun, L.; Bo, D.; Meng, L.; et al. Patient-reported Outcomes of Patients With Breast Cancer During the COVID-19 Outbreak in the Epicenter of China: A Cross-sectional Survey Study. Clin. Breast Cancer 2020, S1526-8209(20)30147-6. [CrossRef] [PubMed]

39. Frey, M.K.; Ellis, A.E.; Zeligs, K.; Chapman-Davis, E.; Thomas, C.; Christos, P.J.; Kolev, V.; Prasad-Hayes, M.; Cohen, S.; Holcomb, K.; et al. Impact of the COVID-19 Pandemic on Quality of Life for Women with Ovarian Cancer. Am. J. Obstet. Gynecol. 2020, S0002-9378(20)30674-8. [CrossRef]

40. Romito, F.; Dellino, M.; Loseto, G.; Opinto, G.; Silvestris, E.; Cormio, C.; Guarini, A.; Minoia, C. Psychological Distress in Outpatients with Lymphoma During the COVID-19 Pandemic. Front. Oncol. 2020, 10, 1270. [CrossRef] [PubMed]

41. Falcone, R.; Grani, G.; Ramundo, V.; Melcarne, R.; Giacomelli, L.; Filetti, S.; Durante, C. Cancer Care During COVID-19 Era: The Quality of Life of Patients with Thyroid Malignancies. Front. Oncol. 2020, 10, 1128. [CrossRef]

42. Fernando, A. Mental Health and Cancer: Why It Is Time to Innovate and Integrate-A Call to Action. Eur. Urol. Focus 2020, S2405-4569(20)30191-7. [CrossRef]

43. Donovan, K.A.; Grassi, L.; McGinty, H.L.; Jacobsen, P.B. Validation of the Distress Thermometer worldwide: State of the science. Psycho-Oncology 2013, 23, 241-250. [CrossRef]

44. Grassi, L.; Spiegel, D.; Riba, M. Advancing psychosocial care in cancer patients. F1000Research 2017, 6, 2083. [CrossRef]

45. Hinz, A.; Friedrich, M.; Kuhnt, S.; Zenger, M.; Schulte, T. The influence of self-efficacy and resilient coping on cancer patients' quality of life. Eur. J. Cancer Care 2018, 28, e12952. [CrossRef]

46. Sinclair, V.G.; Wallston, K.A. The Development and Psychometric Evaluation of the Brief Resilient Coping Scale. Assessment 2004, 11, 94-101. [CrossRef]

47. Ludolph, P.; Kunzler, A.M.; Stoffers-Winterling, J.; Helmreich, I.; Lieb, K. Interventions to Promote Resilience in Cancer Patients. Dtsch. Aerzteblatt Online 2019, 51-52, 865-872. [CrossRef] [PubMed]

48. Rosenberg, A.R.; Bradford, M.C.; McCauley, E.; Curtis, J.R.; Wolfe, J.; Baker, K.S.; Yi-Frazier, J.P. Promoting resilience in adolescents and young adults with cancer: Results from the PRISM randomized controlled trial. Cancer 2018, 124, 3909-3917. [CrossRef] [PubMed]

49. Mack, J.W.; Smith, T.J. Reasons Why Physicians Do Not Have Discussions About Poor Prognosis, Why It Matters, and What Can Be Improved. J. Clin. Oncol. 2012, 30, 2715-2717. [CrossRef] [PubMed]

50. Hagerty, R.; Butow, P.; Ellis, P.M.; Lobb, E.A.; Pendlebury, S.C.; Leighl, N.; Mac Leod, C.; Tattersall, M.H.N. Communicating with Realism and Hope: Incurable Cancer Patients' Views on the Disclosure of Prognosis. J. Clin. Oncol. 2005, 23, 1278-1288. [CrossRef]

51. Husson, O.; Zebrack, B.J.; Aguilar, C.; Hayes-Lattin, B.; Cole, S. Cancer in adolescents and young adults: Who remains at risk of poor social functioning over time? Cancer 2017, 123, 2743-2751. [CrossRef]

52. Masi, C.M.; Chen, H.-Y.; Hawkley, L.C.; Cacioppo, J.T. A Meta-Analysis of Interventions to Reduce Loneliness. Pers. Soc. Psychol. Rev. 2010, 15, 219-266. [CrossRef] 
53. Harris, J.; Cheevers, K.; Armes, J. The emerging role of digital health in monitoring and supporting people living with cancer and the consequences of its treatments. Curr. Opin. Support. Palliat. Care 2018, 12, $268-275$. [CrossRef]

54. Gebbia, V.; Piazza, D.; Valerio, M.R.; Borsellino, N.; Firenze, A. Patients with Cancer and COVID-19: A WhatsApp Messenger-Based Survey of Patients' Queries, Needs, Fears, and Actions Taken. JCO Glob. Oncol. 2020, 6, 722-729. [CrossRef]

55. Weeks, J.C.; Cook, E.F.; O’Day, S.J.; Peterson, L.M.; Wenger, N.; Reding, U.; Harrell, F.E.; Kussin, P.; Dawson, N.V.; Connors, A.F.; et al. Relationship Between Cancer Patients' Predictions of Prognosis and Their Treatment Preferences. JAMA 1998, 279, 1709-1714. [CrossRef]

56. Survey Monkey Security and Compliance. Available online: https://www.surveymonkey.com/mp/datasecurity-and-compliance/ (accessed on 1 June 2020).

57. Fayers, P.; Aaronson, N.K.; Bjordal, K.; Groenvold, M.; Curran, D.; Bottomley, A. EORTC QLQ-C30 Scoring Manual, 3rd ed.; European Organisation for Research and Treatment of Cancer: Brussels, Belgium, 2001.

58. Russell, D.W. UCLA Loneliness Scale (Version 3): Reliability, Validity, and Factor Structure. J. Pers. Assess. 1996, 66, 20-40. [CrossRef]

(C) 2020 by the authors. Licensee MDPI, Basel, Switzerland. This article is an open access article distributed under the terms and conditions of the Creative Commons Attribution (CC BY) license (http://creativecommons.org/licenses/by/4.0/). 